\title{
40. GEOTECHNICAL AND HYDROGEOLOGICAL PROPERTIES OF SEDIMENTS FROM MIDDLE VALLEY, NORTHERN JUAN DE FUCA RIDGE ${ }^{1}$
}

\author{
A.T. Fisher, ${ }^{2}$ K. Fischer, ${ }^{3}$ D. Lavoie,${ }^{3}$ M. Langseth, ${ }^{4}$ and J. $\mathrm{Xu}^{5}$
}

\begin{abstract}
Whole-round core samples were taken from shallow piston cores during Leg 139 for shore-based consolidation and permeability testing. Samples were tested to determine their one-dimensional consolidation and rebound characteristics under increasing effective stresses. At each consolidation step, samples were also tested for intrinsic permeability using the constant flow method. Residues from the consolidation tests were analyzed for primary composition and grain-size distribution; grain-size analyses were also performed on shipboard physical properties sample residues. The rebound characteristics of the whole-round samples are related to grain-size distribution and local heat flow through an empirically derived consolidation index (CI), which was calculated based on results of whole-round tests. A CI value was calculated for each physical properties sample so that rebound corrections could be applied to individual measurements. An empirical permeability index (PI) similarly relates permeability to grain-size distribution, porosity, and clay content. PI values were calculated for each of the physical properties samples to estimate the distribution of permeability with depth in shallow Middle Valley sediments at Ocean Drilling Program Sites 856, 857, and 858. These calculated permeability vs. depth trends were used to estimate the cumulative hydraulic impedance of shallow sediment layers at each site. Shallow sediment samples from immediately adjacent to hydrothermal vents at Site 858 have higher hydraulic impedance, by a factor of 5 10, than sediments at the same site slightly farther from vents. It is not clear whether the lower permeabilities immediately adjacent to active vents are a direct result of diagenesis related to hydrothermal venting, or whether initially lower permeabilities led to the formation of vents in these locations. The consolidation and permeability characteristics of Sample 139-856B-2H-2, 122-137 cm, from the edge of a hill near a massive sulfide mound, were anomalous. The observed behavior of this sample cannot be explained by apparent burial to a greater depth some time in the past, but may reflect the presence of disseminated sulfide, as revealed through electron microscopy.
\end{abstract}

\section{INTRODUCTION}

Middle Valley is unusual in comparison to most seafloor-spreading centers, because a thick blanket of sediments covers the active ridge axis, modifying the style of crustal accretion. New magma rises from beneath the ridge, and then spreads laterally and solidifies within the sediments without reaching the seafloor. Heat-flow calculations, based on measurements made at all four Ocean Drilling Program (ODP) Leg 139 drill sites, indicate that conductive vertical transfer dominates heat transport (Davis, Mottl, Fisher, et al., 1992). This result taken by itself suggests that vertical advection of both heat and mass should be relatively unimportant in comparison to diffusion at the drill sites, at least at the present time over the depths to which temperatures in the sediments were measured directly.

This interpretation of heat transfer processes must be treated cautiously, however, as the presence of active venting in Middle Valley today requires that there be a vigorously active hydrogeological system, with components of both horizontal and vertical flow, at least on a local scale. For example, high temperatures are present in sediments at Site 858 and immediately south of Site 856. In addition, strong lateral gradients in heat flow across Middle Valley, and thus temperature at comparable depths, must induce lateral fluid pressure gradients. The apparent horizontal continuity of turbiditic sedimentary layers (Shipboard Scientific Party, 1992d; Langseth and Becker, this

\footnotetext{
${ }^{1}$ Mottl, M.J., Davis, E.E., Fisher, A.T., and Slack, J.F. (Eds.), 1994. Proc. ODP, Sci. Results, 139: College Station, TX (Ocean Drilling Program).

${ }^{2}$ Department of Geophysics and Ocean Drilling Program, Texas A\&M University, 1000 Discovery Drive, College Station, TX 77845, U.S.A. (Present address: Indiana Geological Survey, 611 N. Walnut Grove, Bloomington, IN 47405).

${ }^{3}$ Marine Geosciences Division, Naval Research Laboratory, Stennis Space Center, MS 39529, U.S.A.

${ }^{4}$ Department of Marine Geology and Geophysics, Lamont-Doherty Earth Observatory, Palisades, NY 10964, U.S.A.

${ }_{5}^{5}$ Department of Civil Engineering, Texas A\&M University, College Station, TX 77843, U.S.A.
}

volume), some of which are quite coarse grained, and lateral contrasts in permeability associated with buried volcanic edifices should induce significant differences in horizontal fluid and heat flow across the drilling area. Finally, the apparent absence of vertical fluid flow through the sedimentary layer at the present time does not rule out the possibility of geochemically and thermally significant fluid flow in the past, particularly if recent heat and fluid fluxes are responsible for transient changes in sediment physical properties. For example, numerical modeling of the sedimented spreading center in Guaymas Basin, Gulf of California, suggests that significant differences in fluid pressures can exist long after the thermal disturbances associated with a volcanic intrusion have dissipated (Fisher and Narasimhan, 1991).

One component of Leg 139 research focused on the physical characterization of the sediment layer overlying the Middle Valley spreading center. This effort included shipboard physical properties measurements (index, thermal, and acoustic properties) conducted on recovered sediments at frequent intervals (typically one or two per section) during the cruise. Unfortunately, measurements made in the laboratory after cores are removed from the seafloor often suffer from the effects of mechanical rebound (expansion) resulting from the removal of confining overburden stresses. Wireline log measurements made deeper in the section better reflect in-situ conditions, but no log data are available for shallow sediments. The first goal of the studies reported here is to define rebound corrections that should be applied to shipboard measurements of basic physical properties in unlithified and semilithified sediments.

A second goal of these studies is to characterize the geotechnical and hydrogeological properties of Middle Valley sediments. These properties affect directly the intensity and extent of hydrothermal activity over a range of fluid velocities and temperatures. Constitutive relationships determined for properties such as permeability can be applied throughout the shallow sediment layer, using corrected shipboard physical properties measurements as a guide, to estimate the overall influence of the sediments on the underlying hydrothermal system. Finally, measurements of sediment consolidation properties can reveal a crude stress history, as sediments may retain an indication 
Table 1. Summary of samples collected for geotechnical and hydrogeological studies.

\begin{tabular}{|c|c|c|c|c|c|c|c|}
\hline \multirow{3}{*}{$\begin{array}{l}\text { Core, section, } \\
\text { interval }(\mathrm{cm})\end{array}$} & \multirow{3}{*}{$\begin{array}{l}\text { Depth } \\
\text { (mbsf) }\end{array}$} & \multirow{3}{*}{$\begin{array}{c}\text { Effective } \\
\text { overburden } \\
\text { stress }^{a}(\mathrm{kPa})\end{array}$} & \multirow{3}{*}{$\begin{array}{c}\text { Heat } \\
\text { flow } \\
\left(\mathrm{W} / \mathrm{m}^{2}\right)\end{array}$} & \multicolumn{3}{|c|}{ Grain size ${ }^{b}$} & \multirow{3}{*}{$\begin{array}{l}\text { Water content } \\
\text { (\% dry weight) }\end{array}$} \\
\hline & & & & Sand & Silt & Clay & \\
\hline & & & & \multicolumn{3}{|c|}{ (\% dry weight) } & \\
\hline \multicolumn{8}{|l|}{$139-856 \mathrm{~B}-$} \\
\hline $2 \mathrm{H}-2,122-137$ & 4.5 & 23 & 1.7 & 1.7 & 53.6 & 42.7 & 48.4 \\
\hline $4 \mathrm{H}-4,122-137$ & 26.5 & 172 & 1.7 & 2.0 & 59.1 & 38.9 & 56.3 \\
\hline \multicolumn{8}{|l|}{ 139-857A- } \\
\hline $4 \mathrm{H}-4,122-137$ & 27.6 & 164 & 0.7 & 4.9 & 68.3 & 26.8 & n.d. \\
\hline $6 \mathrm{H}-4,122-137$ & 46.6 & 300 & 0.7 & 1.0 & 26.2 & 72.8 & 64.6 \\
\hline Duplicate & & & & 0.9 & 26.3 & 72.8 & 61.5 \\
\hline Duplicate & & & & n.d. & n.d. & n.d. & 54.1 \\
\hline \multicolumn{8}{|l|}{ 139-857B. } \\
\hline $2 \mathrm{H}-2,122-137$ & 6.1 & 30 & 0.8 & 0.9 & 52.1 & 47.1 & 69.4 \\
\hline Duplicate & & & & 1.6 & 43.3 & 55.2 & 71.5 \\
\hline $2 \mathrm{H}-5,122-137$ & 10.6 & 51 & 0.8 & 0.8 & 49.7 & 49.6 & 82.8 \\
\hline Duplicate & & & & 1.3 & 39.0 & 59.7 & n.d. \\
\hline $3 \mathrm{H}-6,135-150$ & 29.9 & 183 & 0.8 & 0.4 & 46.2 & 53.5 & 51.1 \\
\hline \multicolumn{8}{|l|}{$139-858 \mathrm{~A}-$} \\
\hline $2 \mathrm{H}-3,126-14 \mathrm{I}$ & 6.7 & 27 & 1.9 & 2.2 & 29.4 & 68.4 & 111.5 \\
\hline Duplicate & & & & 1.5 & 29.3 & 69.1 & n.d. \\
\hline $4 \mathrm{H}-4,122-137$ & 27.1 & 153 & 1.9 & 48.3 & 51.7 & 0.0 & 60.5 \\
\hline $6 \mathrm{H}-2,122-137$ & 43.1 & 267 & 1.9 & 19.2 & 46.6 & 34.2 & 32.2 \\
\hline \multicolumn{8}{|l|}{ 139-858B- } \\
\hline $1 \mathrm{H}-4,126-14 \mathrm{I}$ & 5.8 & 25 & 10.8 & 0.4 & 46.7 & 53.0 & 92.8 \\
\hline Duplicate & & & & n.d. & n.d. & n.d. & 87.0 \\
\hline \multicolumn{8}{|l|}{$139-858 \mathrm{C}$} \\
\hline 5H-4, 122-137 & 29.2 & 200 & 3.3 & 19.7 & 66.9 & 13.4 & 63.4 \\
\hline $7 \mathrm{H}-1,122-137$ & 42.7 & 309 & 3.3 & 48.9 & 40.3 & 10.8 & 45.4 \\
\hline
\end{tabular}

Note: n.d. $=$ not determined, usually in the case of duplicate samples.

${ }^{a}$ The mean of values determined with direct and indirect methods (equations 1 and 2), as described in the text.

${ }^{b}$ Grain-size analyses were conducted using the method described in the Appendix. Additional data from Leg 139 physical-properties residues are also presented in the Appendix.

of their previous maximum overburden stress, in conjunction with a diagenetic record.

\section{GEOLOGICAL AND GEOPHYSICAL CONTEXT OF LEG 139 SITES AND SAMPLES}

Piston coring was limited to shallow depths throughout Leg 139 drilling, owing to the presence of massive and disseminated sulfide, hard diagenetic boundaries, and lithified turbidites close to the seafloor (Davis, Mottl, Fisher, et al., 1992). The sediment samples tested for this study had a wide range of grain-size distributions, initial void ratios, and in-situ thermal gradients, however, making it possible to interpret the results over a broad lateral and vertical extent. In this regard, the discussion in the following sections deals with all tested samples together, rather than on a site by site basis. For convenience, samples are referenced throughout this paper using incomplete nomenclature of site-hole-core-section, rather than including leg and interval information; complete sample identification is provided in Table 1.

Samples from Site 856 were collected from Hole 856B, on the edge of an uplifted mound of turbidites which forms a 500 -m-diameter hill (Fig. 1). The origin of this hill, and its relationship to a massive sulfide mound and vent site to the south, remain unknown. It is likely that the hill was uplifted sometime after the initiation of sulfide formation, as sediments recovered from Holes $856 \mathrm{~A}$ (near the peak of the hill) and $856 \mathrm{~B}$ contain disseminated sulfide, much of which is detrital and probably originated from the massive sulfide body to the south (Shipboard Scientific Party, 1992b). Heat flow at Hole 856B was determined to be about $1.7 \mathrm{~W} / \mathrm{m}^{2}$. Some nonlinearity in the heat flow with depth at Hole 856B may reflect extreme variations in thermal conductivity associated with the nearby sulfide mound (Shipboard Scientific Party, 1992b). Additional holes were drilled in a transect across the sulfide mound, but no samples from the mound itself were subjected to consolidation or permeability testing.

Samples from Site 857 were collected from cores from Holes $857 \mathrm{~A}$ and $857 \mathrm{~B}$, where heat flow was about $0.7 \mathrm{~W} / \mathrm{m}^{2}$, the lowest of all holes piston cored during Leg 139 (Fig. 1; Shipboard Scientific
Party, 1992c). Holes 857A and 857B were drilled about 180 m east of rotary-cored and reentry Holes $857 \mathrm{C}$ and $857 \mathrm{D}$, the latter of which was sealed and instrumented with a reentry-cone CORK (Davis et al., 1992). Piston-cored sediments from Site 857 provide a reference section to which sediments associated with recent uplift and a sulfide deposit (Site 856) and proximity to intense hydrothermal activity (Site 858) can be compared. Site 855, which had the lowest heat flow recorded during Leg 139 (about $0.4 \mathrm{~W} / \mathrm{m}^{2}$ ), might have provided an additional reference but was rotary cored only.

Samples from Site 858 were taken from Holes 858A (heat flow 1.9 $\mathrm{W} / \mathrm{m}^{2}$ ) and $858 \mathrm{C}$ (heat flow $3.3 \mathrm{~W} / \mathrm{m}^{2}$ ), respectively, just outside and inside a hydrothermal vent field. A single sample was also taken from Hole $858 \mathrm{~B}$, about $10 \mathrm{~m}$ from an active vent that is presently discharging $\sim 275^{\circ} \mathrm{C}$ fluid. Heat flow at Holes $858 \mathrm{~B}$ and $858 \mathrm{D}$, based on single shallow measurements near $200^{\circ} \mathrm{C}$ at each location, is about $11 \mathrm{~W} / \mathrm{m}^{2}$. This high heat-flow value was expected for Hole 858B, purposely situated adjacent to an active vent, but was somewhat surprising for Hole $858 \mathrm{D}$, which was located farther from known vents (although well within the boundaries of the local heat flow high).

\section{METHODOLOGY}

\section{Laboratory Tests}

Details of consolidation and permeability test methods are included in the Appendix. Fourteen whole-round samples were collected from piston cores as soon as the core liners were pulled from the core barrels and set out on the catwalk of JOIDES Resolution. These samples were taken at all sites where piston cores were collected, at depths of 4-47 $\mathrm{m}$ below seafloor (mbsf). A listing of samples, calculated in-situ overburden stress, local heat flow, and grain-size distribution appears in Table 1. All pressures reported in this paper are in units of $\mathrm{kPa}$, whereas permeabilities are intrinsic, in units of $\mathrm{m}^{2}$ (one darcy $=10^{-3} \mathrm{~cm} / \mathrm{s} \approx$ $10^{-12} \mathrm{~m}^{2}$ ). Subsamples were collected prior to and after consolidation testing for examination under transmission electron microscopy (TEM), in directions both parallel and perpendicular to the long axis of the cores. TEM preparation methods are also listed in the Appendix.

Leg 139 shipboard physical properties results (index properties, compressional-wave velocity, and thermal conductivity) are described individually for each site, with methodologies described in detail in the Initial Reports volume (Davis, Mottl, Fisher, et al., 1992). Sediment index properties were measured for each consolidation/permeability sample with the same methods used during Leg 139 . In addition, the general grain-size distribution of the Leg 139 consolidation and permeability samples was determined using a modified Folk (1974) method to separate and weigh materials with different "effective" diameters, $d$ : clay $(d \leq 4 \mu \mathrm{m})$, silt $(4 \mu \mathrm{m}<d \leq 63 \mu \mathrm{m})$, and sand $(d>63 \mu \mathrm{m})$. The same method was used for all shipboard physical properties residues that were not too lithified to disaggregate in a $4 \mathrm{~g} / \mathrm{L}$ hexametaphosphate (Calgon) solution; results of these analyses and a more complete description of laboratory methods are also reported in the Appendix. The bulk mineralogy of consolidation and permeability samples, and the clay mineralogy of these samples plus the physical properties residues were subjected to $\mathrm{x}$-ray diffraction (XRD). Clay XRD results were not available as of the publication deadline for this paper, and will be published elsewhere.

\section{Analytical Procedures}

The consolidation state of each sample was determined from the form of void ratio vs. effective stress curve, plotted on a semilogarithmic scale $\left(e-\log \sigma^{\prime}\right)$, i.e., a comparison of apparent preconsolidation stress, $\sigma_{0}{ }^{\prime}$ to the present effective overburden stress, $\sigma_{e}{ }^{\prime}$. The effective overburden stress for each sample was determined in two ways, both of which yielded similar results. First, $\sigma_{e}{ }^{\prime}$ was calculated directly from shipboard physical properties measurements as

$$
\sigma_{e}^{\prime}=\sum_{i=1}^{n}\left(\rho_{b i}-\rho_{w}\right) g\left(z_{i}-z_{i-1}\right),
$$


$128^{\circ} 50^{-}$

$128^{\circ} 40^{\prime}$

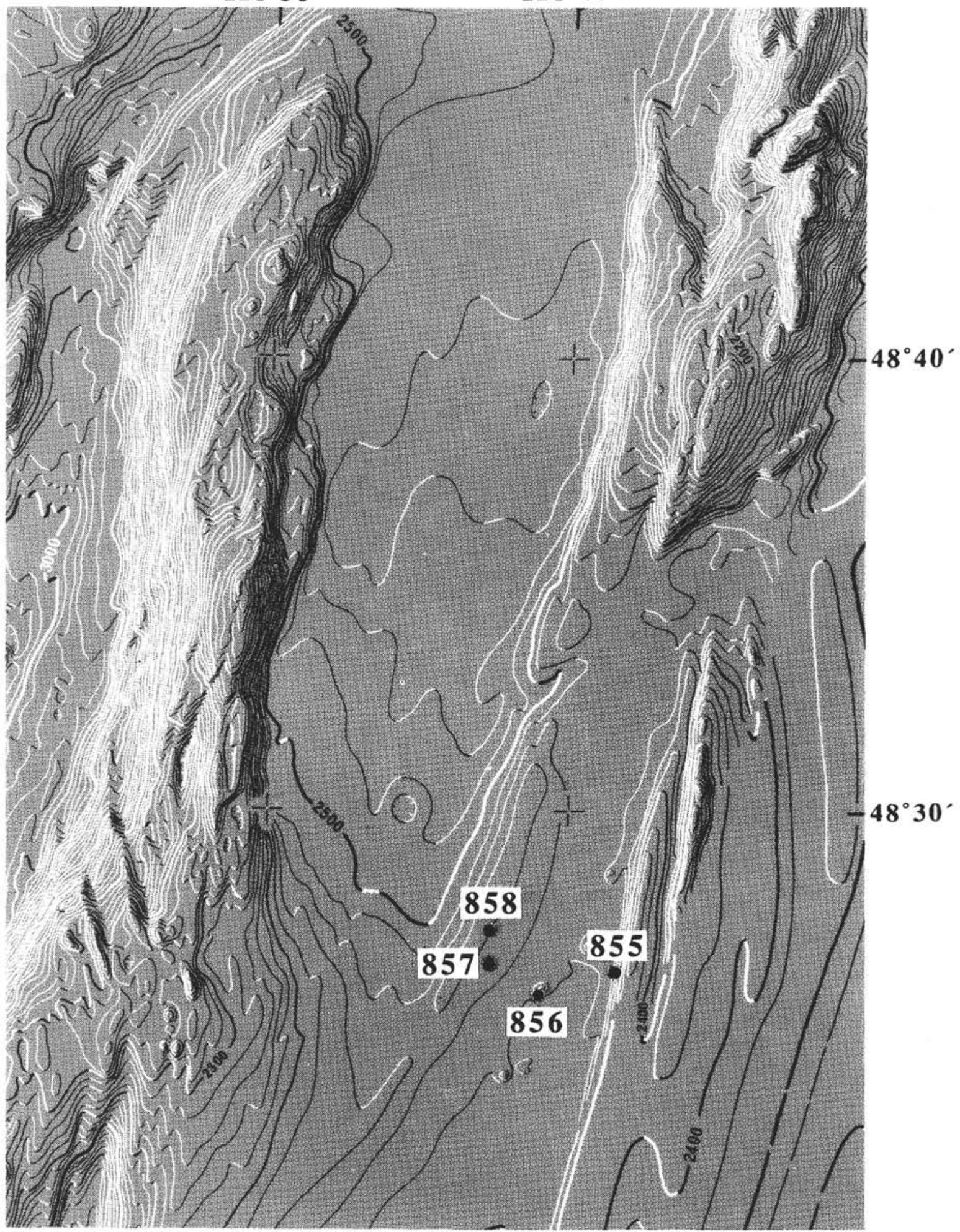

Figure 1. Location of Leg 139 sites in Middle Valley, with water depths in meters. 
Table 2. Results of consolidation testing of Leg 139 whole-round sediment samples.

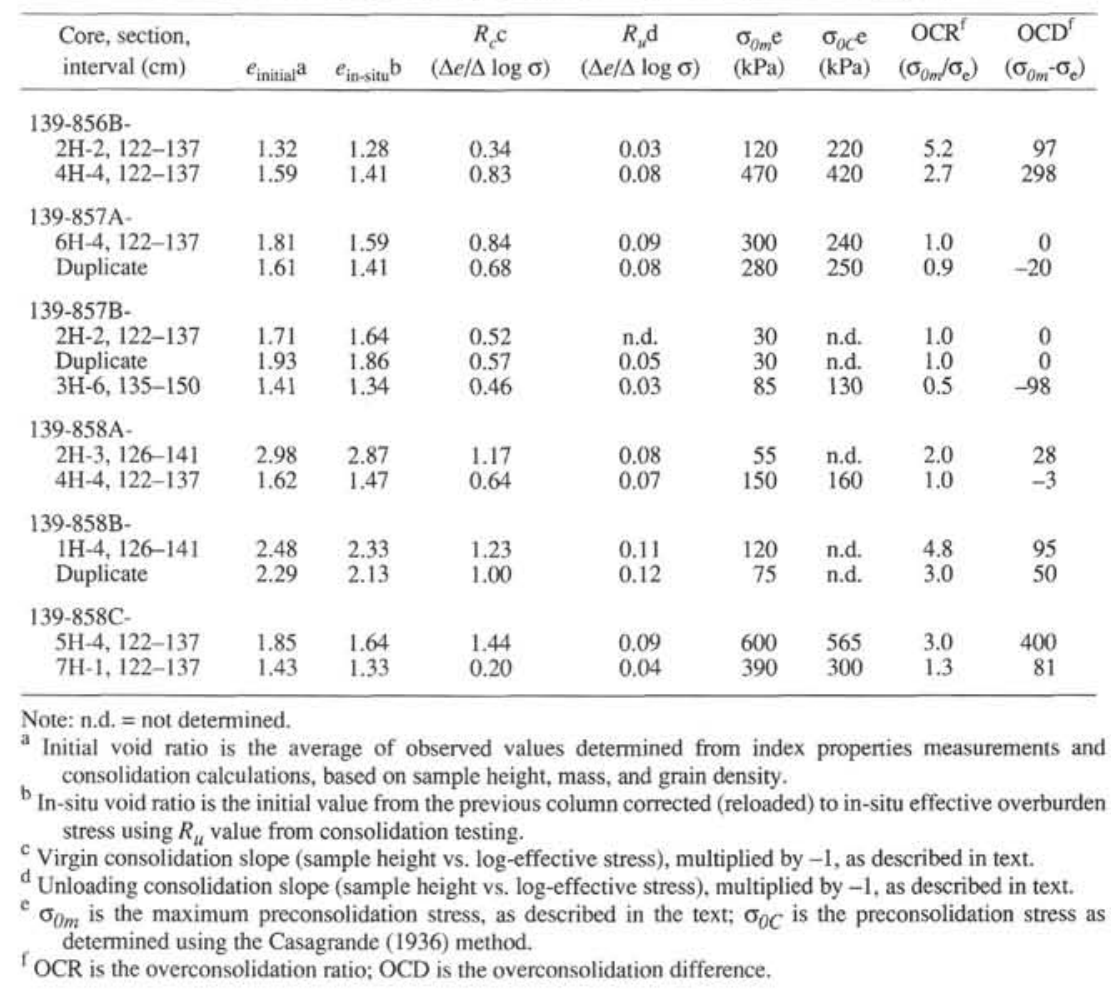

where $\rho_{b i}$ is sediment wet-bulk density at depth $z_{i}, \rho_{w}$ is pore-water density (assumed to be constant $\left.\approx 1.04 \mathrm{~g} / \mathrm{cm}^{3}\right),\left(z_{i}-z_{i-1}\right)$ is the depth between the present and overlying $\rho_{b}$ measurement, $g$ is gravitational acceleration, and $n$ is the present sample number. The second method of calculating effective overburden stress required fitting shipboard wet-bulk density data for each hole with a curve of the form $\rho_{b}(z)=$ $\mathrm{a} z^{\mathrm{b}}$, where $a$ and $b$ are constants, then solving an integral form of equation (1),

$$
\sigma_{e}^{\prime}=\int_{0}^{z_{1}}\left[\rho_{b}(z)-\rho_{w}\right] g d z
$$

where the difference between sediment bulk density and fluid density is defined by the best-fitting exponential equation.

This effective overburden stress was compared to the apparent preconsolidation stress, $\sigma_{\mathrm{o}}{ }^{\prime}$, the greatest effective stress that the sediment appears to have experienced in the past. The apparent preconsolidation stress is generally calculated using the graphical method of Casagrande (1936) or some modification of this method. The Casa-grande method is thought to underestimate the true maximum effective stress in many cases (Bryant et al., 1986), but values derived using this method are still useful for comparative purposes.

The preconsolidation stresses we believe to be more characteristic of the samples we tested were calculated with the following method (Fig. 2). Each sample was step-loaded (generally to a maximum effective stress of about $2300 \mathrm{kPa}$ ) to determine the slopes $R_{r}$ and $R_{c}$ of the reloading and virgin consolidation segments, respectively. These parameters are referred to as compression indices by Lambe and Whitman (1969) and many others, but we chose a slightly different nomenclature to avoid confusion with additional parameters defined later in this paper. The sample was then unloaded to determine the mechanical rebound slope, $R_{u}$. In many cases this unloading slope was the same as the reloading slope, although the former can be difficult to determine if the sample is greatly overconsolidated. Reloading, virgin, and unloading slopes are all negative, as the samples are compressed and lose volume with increasing loads, and recover some volume when loads are removed. For simplicity, we drop the negative signs for these slopes throughout this paper.

The reloading and unloading slopes were used to estimate the void ratio that the sample had before it was removed from the seafloor (through virtual reapplication of the calculated effective overburden stress); calculation of this initial void ratio then allowed direct estimation of the maximum preconsolidation stress, $\sigma_{\text {om }}^{\prime}$, from interpolation of the virgin consolidation curve (Fig. 2). This method is similar to that described by Bryant and Bennett (1988), with their result labeled $\sigma_{C 5}^{\prime}$.

Use of the Casagrande method also requires that the transition from reloading to virgin consolidation curves be well defined, which was rarely true with our samples; we used the Casagrande method to calculate an apparent preconsolidation stress, $\sigma_{o c}^{\prime}$, where possible, but believe that our calculated maximum preconsolidation stresses are more accurate estimates of in-situ conditions. For each sample, the maximum preconsolidation stress was compared to the effective overburden stress to determine the overconsolidation ratio (OCR, $\left.\sigma_{o m}^{\prime} / \sigma_{e}^{\prime}\right)$ and the overconsolidation difference $\left(\mathrm{OCD}, \sigma_{o m}^{\prime}-\sigma_{e}^{\prime}\right)$, as defined by Bryant and Bennett (1988).

Most of the consolidation samples were $\mathrm{x}$-rayed to locate and avoid nodules and extremely coarse zones, both of which can contribute to problems with sample preparation and testing. The results presented here are thus mainly for the moderate- to fine-grained portion of the Leg 139 sediments. We believe that this finer-grained component should dominate the shallow section in terms of vertical permeability, much as the resistivity of a series circuit is dominated by the resistor with the greatest resistance. It should also be possible to draw broad conclusions concerning the coarser-grained layers of the sedimentary column by using our results as a limiting extreme.

\section{PRIMARY RESULTS OF GEOTECHNICAL AND HYDROGEOLOGICAL TESTS}

\section{Consolidation Results}

The results of all one-dimensional consolidation tests of piston core samples are summarized in Table 2, and stress-strain relation- 

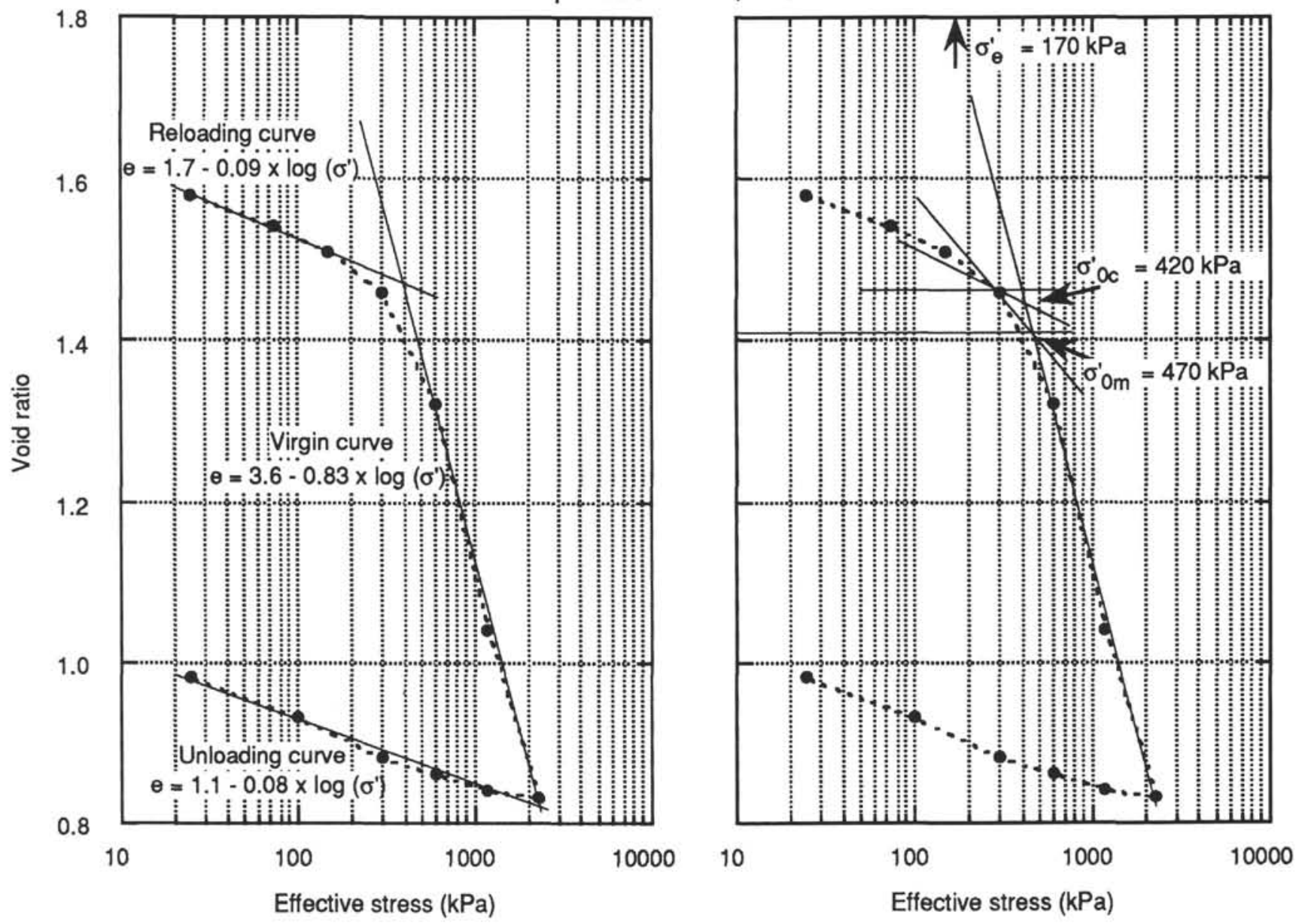

Figure 2. A. Example of stress-strain relationships for a Leg 139, one-dimensional consolidation sample. The plot on the left shows reloading, virgin, and unloading curves. The plot on the right illustrates the relationship between effective overburden stress $\left(\sigma_{e}^{\prime}\right)$, maximum preconsolidation stress $\left(\sigma_{o m}^{\prime}\right)$, and Casagrande $(1936)$ preconsolidation stress $\left(\sigma_{o c}^{\prime}\right)$. B. Stress-strain plots for all other Leg 139 samples, with best-fitting linear reloading, virgin, and unloading curves.

ships are plotted in Figure 2. Nearly all samples revealed characteristic reloading, virgin consolidation, and unloading trends. In general, samples from Site 857 are normally to slightly underconsolidated, whereas those from Sites 856 and 858 are overconsolidated (Table 2). Virgin consolidation slopes $\left(R_{c}\right)$ vary from 0.2 (highly lithified Sample $858 \mathrm{C}$ $7 \mathrm{H}-1$ ) to about $1.17-1.23$ (very high-water-content Samples $858 \mathrm{~A}-$ $2 \mathrm{H}-3$ and $858 \mathrm{~B}-1 \mathrm{H}-4)$. Sample $858 \mathrm{C}-5 \mathrm{H}-4$ also had an apparently high $R_{c}$ value, but damage and remolding during sample preparation probably contributed to this value. Sample $856 \mathrm{~B}-2 \mathrm{H}-2$ was anomalous; it originated at a shallow depth, but behaved as if it was from a deeper level. The initial water content of this sample was relatively low (48\%) and its $R_{c}$ value was just 0.34 , the second lowest measured. During preparation it was also determined that this sample contained numerous pieces ( $\leq 1 \mathrm{~mm}$ in diameter) of disseminated pyrite, as is common throughout the sediments from Holes $856 \mathrm{~A}$ and $856 \mathrm{~B}$.

Shallow Sample 857B-2H-2 (6.1 mbsf) displayed no reloading trend; all consolidation steps moved the sample down a virgin consolidation curve (Fig. 2, Table 2). In contrast, shallow Samples 856B$2 \mathrm{H}-2$ (4.5 mbsf), 858A-2H-3 (6.7 mbsf), and 858B-1H-4 (5.8 mbsf) yielded reloading curves during initial consolidation steps, indicating some apparent overconsolidation. Indeed, these samples have OCRs of 5.2, 2.0, and 3.0-4.8 (tested twice), respectively. Apparent overconsolidation of shallow marine clays is common, and is generally attributed to processes such as early cementation and electrical interparticle bonding (Bryant and Bennett, 1988). The overconsolidation of young, shallow samples from Sites 856 and 858 may have resulted in part because higher heat flow (in comparison to Sample 857B-2H2) accelerated rates of diagenesis. The OCD for Sample 856B-2H-2 was also high, about $100 \mathrm{kPa}$, approximately equivalent to that expected if $20 \mathrm{~m}$ of sediment had recently eroded (slumped) from the area where Hole 856B was drilled, as was hypothesized based on paleomagnetic and sedimentologic indications (Shipboard Scientific Party, 1992b).

Sample 856B-2H-2 also behaved anomalously in terms of its rebound characteristics, yielding a $R_{u}$ value of just 0.03 , close to the values for much deeper Samples $858 \mathrm{C}-7 \mathrm{H}-1$ and $857 \mathrm{~B}-3 \mathrm{H}-6$. Finally, Sample $856 \mathrm{~B}-2 \mathrm{H}-2$ had the lowest in-situ void ratio, 1.28 (calculated from the initial measured void ratio, with a correction along the reloading/unloading path to in-situ conditions), yet a moderate final void ratio of 0.84 at extreme consolidation of $2333 \mathrm{kPa}$ (equivalent to about $250 \mathrm{~m}$ sediment depth). The low in-situ void ratio and the relatively small porosity loss under load both may be partly attributed to the sample having a low-to-moderate clay content and containing numerous disseminated pyrite crystals.

It is clear from the preceding discussion that grain-size distribution and other characteristics related to in-situ heat flow contribute directly to laboratory consolidation properties in the Leg 139 samples. These factors actually may be proxies for the true controls on consolidation and permeability trends, sediment strength, and pore volume and shape. Also, as clay particles become lithified, they tend to form aggregates that act as a "grain unit" rather than as individual particles. In order to extrapolate the trends detected in a few consoli- 

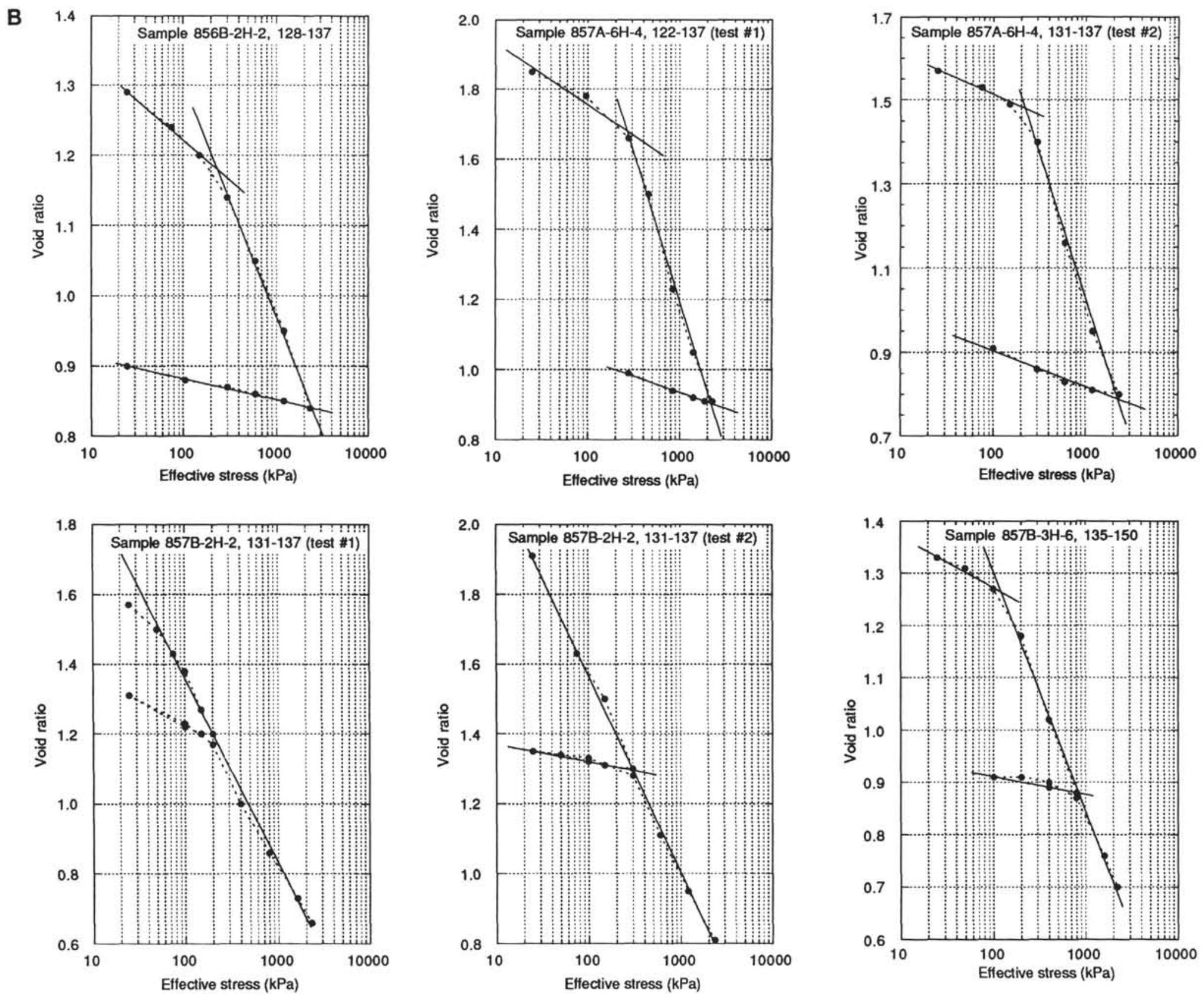

Figure 2 (continued). 

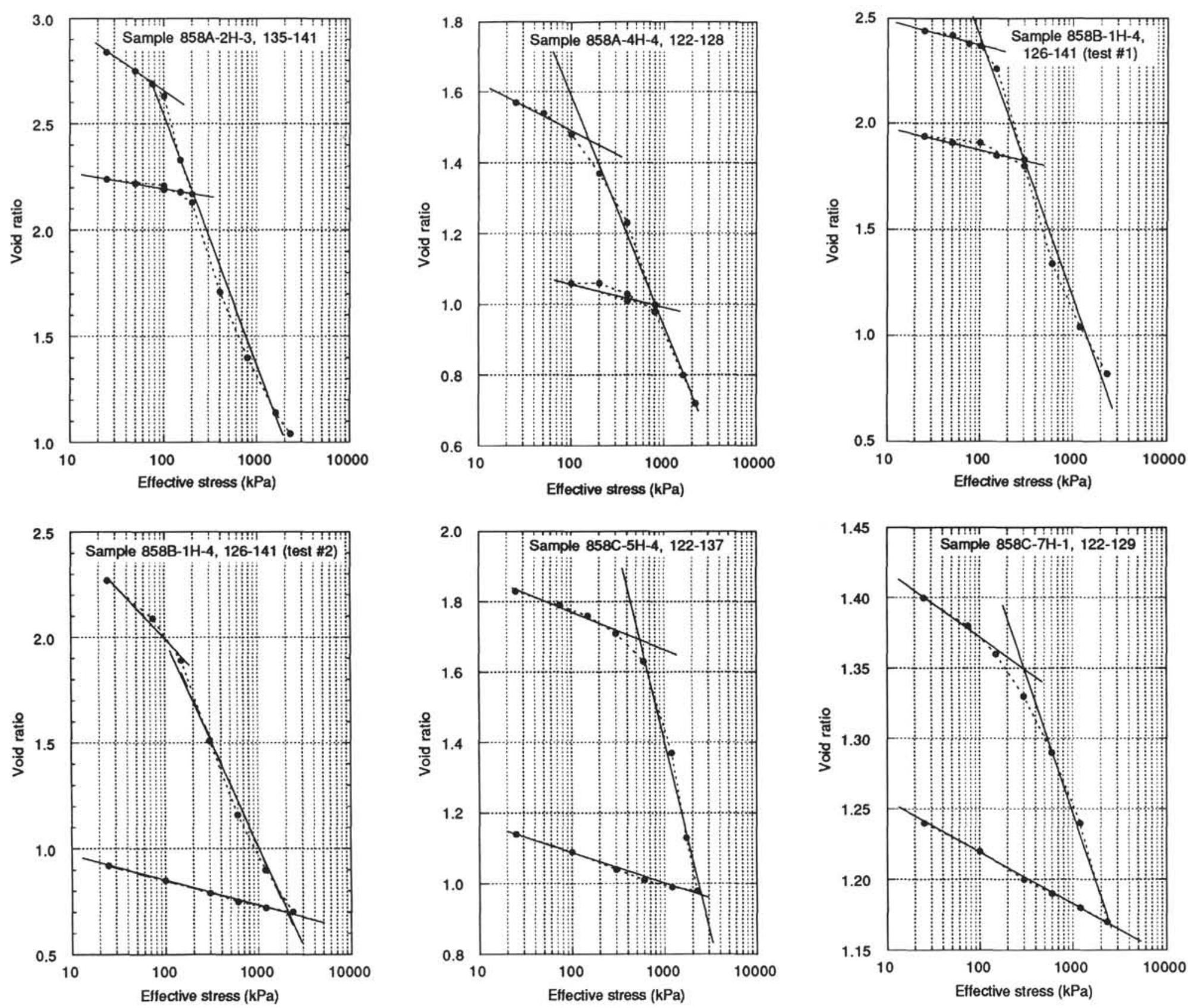

Figure 2 (continued). 
dation samples to the Leg 139 results overall, we established an empirical relationship between grain size, heat flow, and consolidation behavior, as explained in the following paragraphs.

It is well known that samples with high clay content are most likely to exhibit standard consolidation behavior. In particular, samples with more silt and sand will retain more of their porosity under load and will not rebound to the same extent when unloaded. The greater retention of porosity results because larger grains cannot be rearranged to pack as tightly as smaller grains. In addition, the smaller clay grains tend to be pancake shaped, rather than spherical; flat clay particles can become preferentially oriented during packing, allowing the bulk sediment to lose a greater percentage of its original porosity.

It also seems reasonable that, given samples with equal clay contents, those exposed to higher temperatures would become lithified more quickly (through alteration), initially appearing overconsolidated, and finally losing some or all of their elasticity. In fact, a sample with a high clay content from an area of high heat flow may behave much like a low-clay-content sample from an area of low heat flow, because the lithified and altered clay particles could respond to changes in stress more like sand grains. In a sense, this last possibility was accounted for in our grain-size analyses, as clay particles that were sufficiently altered that they would not disaggregate freely could have been interpreted to be sand grains, based on the diameter and hydrodynamic behavior of the aggregates. Rohr and Gröschel-Becker (this volume) also attributed higher-than-expected densities and velocities in shallow sediments at Sites 857 and 858 to diagenesis, although their analysis did not include an examination of trends over a scale of a few meters.

As discussed by Busch (1989), although the standard rebound curves of Hamilton (1976) related mechanical rebound to porosity, porosity was actually used as a proxy for in-situ overburden stress, which is the true independent variable. We have derived a continuum of curves relating the rebound of sediment porosity [via void ratio, $e$ $=\phi /(1-\phi)]$ to the change in sample effective stress when the sample is removed from the seafloor, $\Delta e=R_{u}(q, c) \times\left(\Delta \log \sigma_{e}^{\prime}\right)$. In this formulation $R_{u}$ is assumed to be a function of clay content, $c$, and background heat flow, $q$.

We first calculated an empirical consolidation index, $C I$, which we use to relate $R_{u}$ to clay content and heat flow. After significant trial and error, we defined the consolidation index to be

$$
C I=\left[\frac{\sqrt[3]{(1-C)}}{q^{0.6}}\right]
$$

where $c$ is the decimal clay fraction of the sample (by dry weight, Table 1 ), and $q$ is heat flow, in $\mathrm{W} / \mathrm{m}^{2}$. This formulation is empirical, but it will be demonstrated later that definition of $C I$ using equation (3) allows for a reasonable interpretation and extrapolation of our experimental results. Individual values of $R_{u}$ were then regressed against $C I$ to yield a least-squares, best-fitting line (Fig. 3A). The relatively low $C I$ values for Samples $856 \mathrm{~B}-2 \mathrm{H}-2$ and $858 \mathrm{C}-7 \mathrm{H}-1$, which fall off the general trend, were not included in this regression.

Sample $856 \mathrm{~B}-2 \mathrm{H}-2$ is clearly anomalous, both in terms of its composition and consolidation behavior (and permeability, as discussed later). Sample $858 \mathrm{C}-7 \mathrm{H}-1$ was extremely lithified. One elongate carbonate nodule was removed from the edge of the sample during preparation for consolidation, and replaced with remolded cuttings. Numerous clay particles were cemented into aggregate grains within this sample, requiring rougher treatment than is ideal during preparation for grain-size analyses. Some sand grains may have been crushed during this process, yielding an inaccurate clay content. In addition, this sample underwent little consolidation during testing (retaining an extremely high void ratio of 1.17 at an effective stress of $2333 \mathrm{kPa}$ ) and did not display typical primary and secondary consolidation trends in response to individual step loads, suggesting that its behavior was inelastic (e.g., Lambe and Whitman, 1969; Wood, 1990), and that general consolidation theory probably is not applicable.

We used heat flow, rather than temperature, to calculate $\mathrm{CI}$ values because heat flow indicates proximity to a hydrothermal vent or other local heat source. While temperature is also a proxy for this parameter (and may actually be a more direct indication of thermal "capacity" for diagenesis), the present in-situ temperature of a sample also reflects its depth of origin. The consolidation index as defined here is intended to reflect each sample's behavior throughout burial (i.e., as increasing vertical loads are applied) and exposure (unloading), and thus should not include a depth term. We did experiment with including temperature in the consolidation index in a variety of forms (both with and without heat flow) and found that the inclusion of a temperature term increased the scatter apparent in Figure 3A.

The calculation of $R_{u}$ values (and resulting mechanical rebound) based on equation (3) and the regression shown in Figure 3A should be applied to Leg 139 physical properties data selectively and with care. Only data from samples sufficiently unlithified to exhibit elastic, mechanical rebound should be corrected using these relationships. As an initial cut, all those physical properties samples for which a sediment grain-size distribution could be determined are candidates for correction. Samples that would not disaggregate freely for grain-size analysis would presumably also not follow a mechanical rebound trend when unloaded. The range in clay-size fraction for those samples used to determine rebound is approximately 0-73\% (Tables 1 and 2), covering most (but not all) of the Leg 139 physical properties samples (see Appendix). Of course, application of consolidation theory is most appropriate for samples with moderate to high clay contents. Samples with $>73 \%$ clay would be expected to experience even greater rebound than predicted through our analyses, so application of the empirical relationship for these clay-rich samples is probably conservative. For samples with low clay contents and/or from greater depths below the seafloor than represented by physical properties grain-size analyses, we recommend a rebound correction using $R_{u}=$ 0.03 , the lowest value determined in the laboratory for lithified, claypoor samples (Table 2).

As an example of how the rebound trend defined here can be applied, all of the Leg 139 wet-bulk density data are plotted against void ratio in Figure 4. The trend line defined in the figure is based on the constitutive relationship between bulk density and porosity, $\rho_{b}=$ $\phi \rho_{w}+(1-\phi) \rho_{g}$, where $\rho_{g}$ is grain density calculated for each sample. That most Leg 139 samples cluster tightly around the same trend illustrates that this relationship is broadly applicable; data from samples collected in Hole $856 \mathrm{~A}$, which are more widely scattered than those from other holes, may reflect incomplete drying prior to graindensity determinations. Assuming that the overall trend also defines the sediment rebound path, corrections to the measured void ratios can be determined by calculating CI values for each sample, based on its grain-size distribution and local heat flow. The $R_{u}$ value for any particular sample is calculated from the equation illustrated in Figure $3 \mathrm{~A}$, then used to calculate the in-situ void ratio. Individual data points are then moved along the trend in Figure 4A to determine corrected bulk densities. Applying similar corrections will clearly be more difficult for compressional-wave velocity (Fig. 4B), as concluded by Rohr and Gröschel-Becker (this volume), since there appears to be little difference in velocity over a large range in void ratios. These shipboard data may be strongly affected by microfracturing. A realistic velocity-void ratio trend is now being developed using consolidation samples, which are being tested under load.

Correction of thermal conductivity values may require some additional analysis as well, as there is a strong dependence of this property on grain composition in addition to grain size, based on data collected during Leg 139 (Shipboard Scientific Party, 1992a,b,c,d). It would probably be best to correct conductivities with a transform that includes mean grain conductivities on a site-by-site basis, as mean grain conductivity is site dependent (Davis, Mottl, Fisher, et al., 1992). 


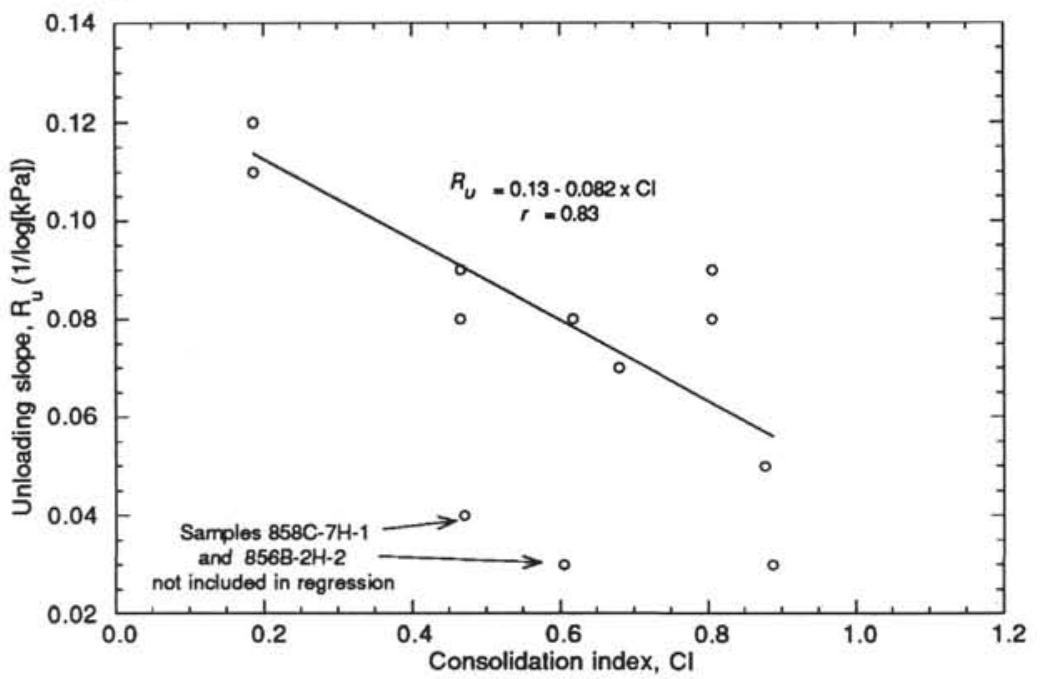

B
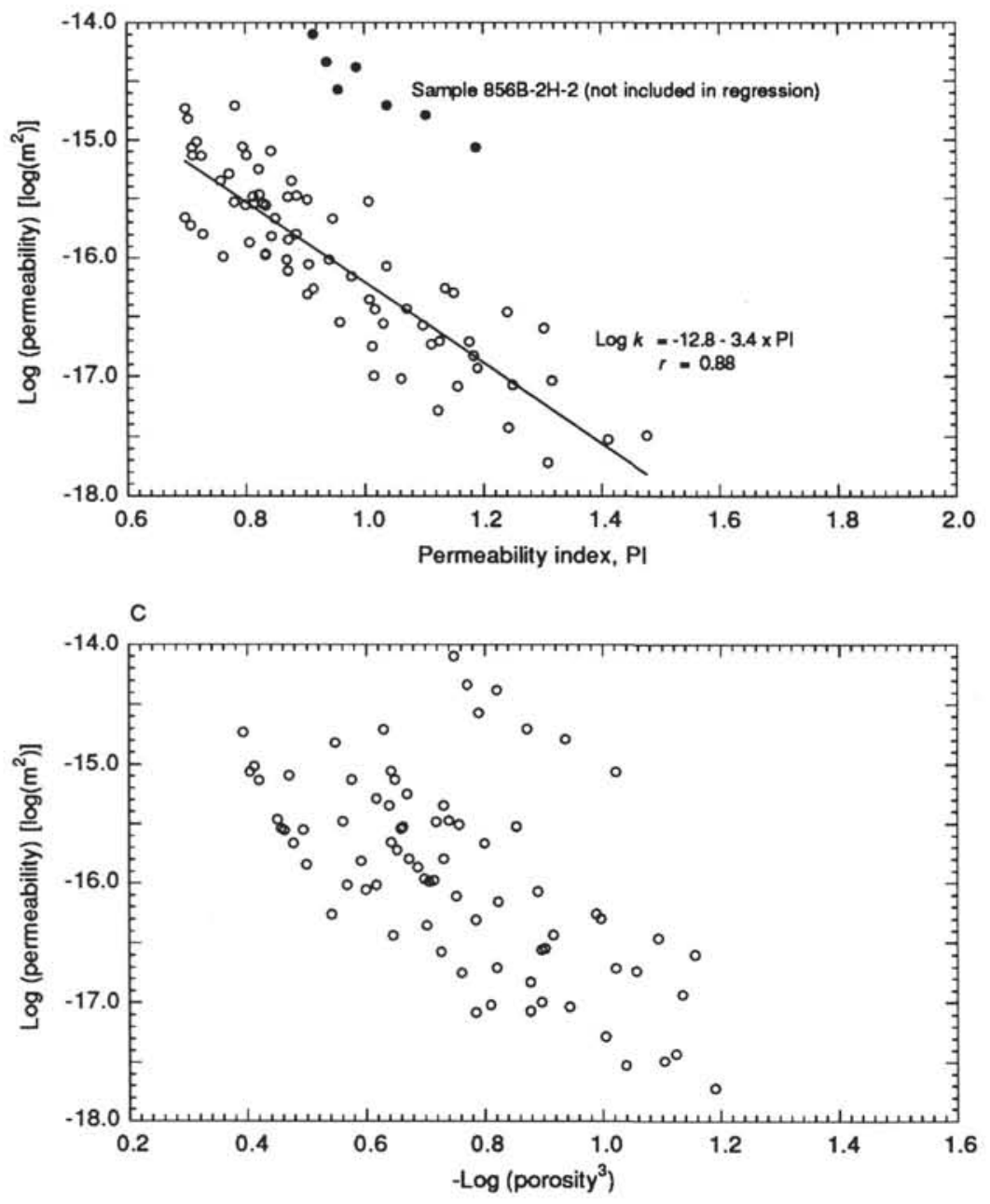

Figure 3. A. Plot relating sediment unloading slope to consolidation index. The empirical consolidation index was first calculated for each geotechnical sample as a function of grain size and local heat flow, according to equation (3). The plot illustrates that mechanical rebound can be related to consolidation index according to the indicated line. Data from Samples $856 \mathrm{~B}-2 \mathrm{H}-2$ and $858 \mathrm{C}-7 \mathrm{H}-1$ were not included in this least-squares best-fit for reasons discussed in the text. B. Plot relating the log of sediment permeability to permeability index. The empirical permeability index was calculated for each geotechnical sample as a function of grain size, local heat flow, and porosity, according to equation (4). The plot illustrates that permeability can be related to $P I$ according to the indicated $\log -\log$ trend. Data from Sample 856B-2H-2 (filled circles) were excluded from the least-squares best-fit for reasons discussed in the text. C. Plot of log permeability to log porosity-cubed. Note that the correlation here is weaker than that in Figure 3B, illustrating that the other factors included in the permeability index (grain size and heat flow) should not be neglected.

\section{Permeability Test Results}

Data from a typical series of permeability tests conducted on a single sample are presented in Figure 5A, and the results of all permeability tests are summarized in Table 3 and Figure 5B. Measured permeabilities $(k)$ tended to vary with void ratio according to the standard relationship of $\log (k)=a+b e$, where $a$ and $b$ are constants (referred to as the permeability intercept and permeability slope, respectively, in Table 3 and later in the text). Several samples were tested twice to verify experimental results. Although there are some differences between tests conducted several months apart on individual whole-round samples, these variations are small compared to vari- 
A

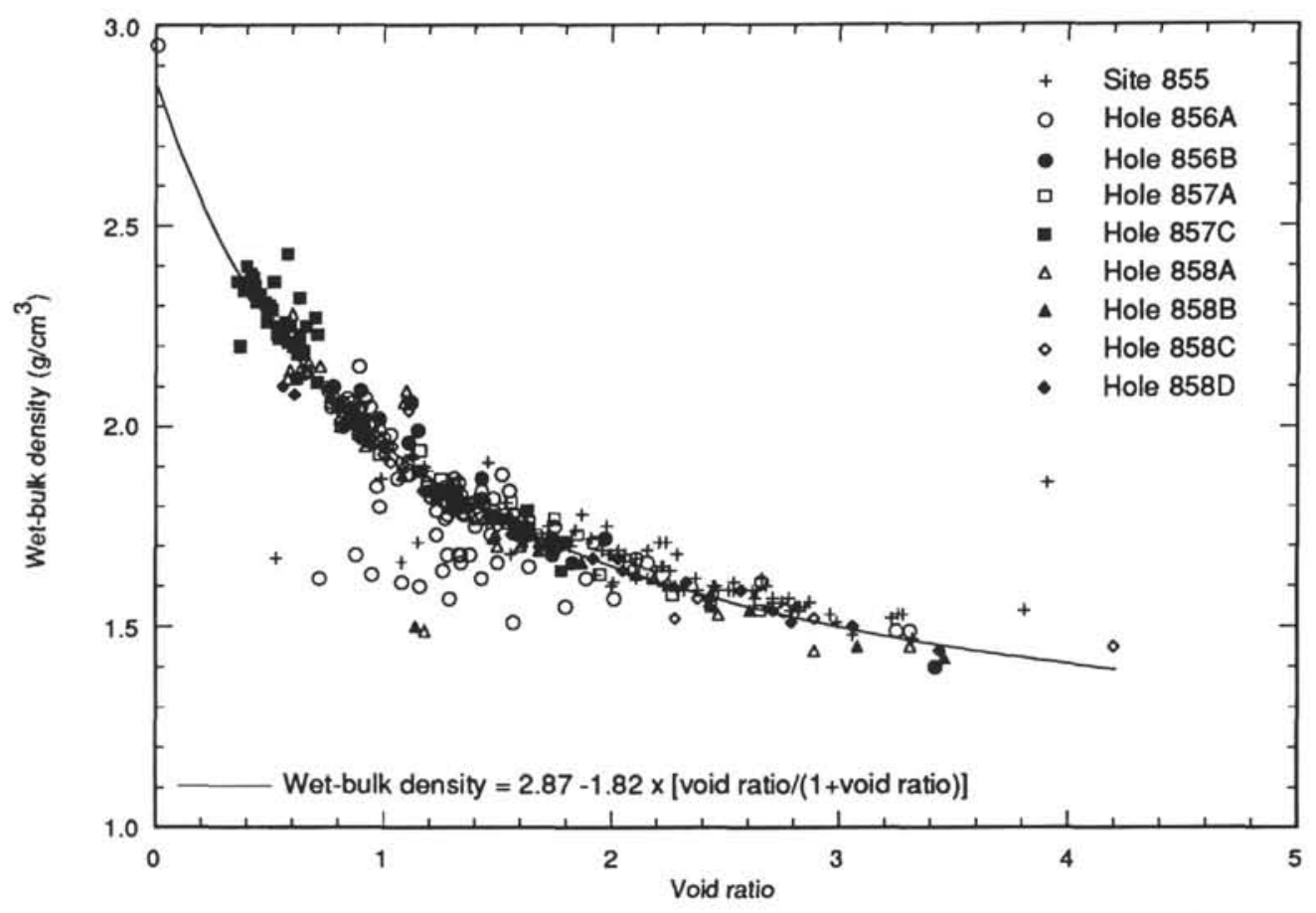

B

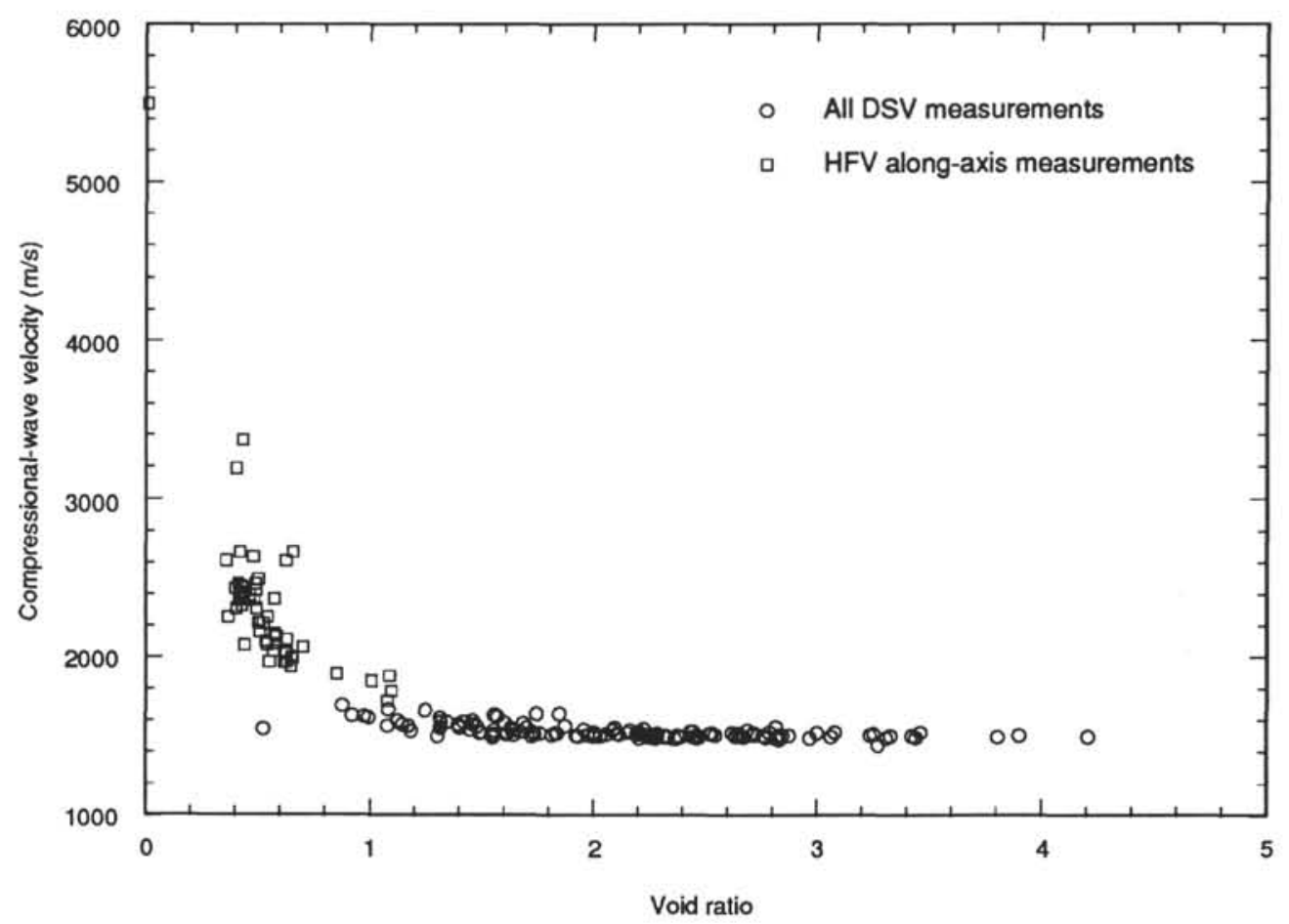

Figure 4. Variations in the physical properties of Leg 139 sediment samples. A. Shipboard measurements of wet-bulk density $\left(\rho_{b}\right)$ vs. void ratio $(e)$. The least-squares best-fitting curve of the form $\rho_{b}=\rho_{g-a} \phi$ is shown, with $\phi=e /(e+1)$. These data have not been corrected for mechanical rebound, but the trend line can be used to define density rebound, once void-ratio rebound is calculated with the relationship defined in Figure 3A. It is not clear why the Hole 856A samples tend to fall off the primary trend; perhaps these were not completely dry when their volumes were determined. B. Shipboard measurements of compressional-wave velocity $\left(V_{p}\right)$ vs. void ratio. The depths of individual measurements were adjusted by $\leq 5 \mathrm{~cm}$ to allow cross-plotting of measurements made at slightly different locations within the recovered core. The data shown were collected along the long axis of cores with the digital sonic velocimeter (DSV), a two-prong device pressed into unconsolidated material, and with a Hamilton frame velocimeter (HFV) for semilithified to lithified material. Measurements perpendicular to the core axis are not shown. The apparent trend clearly reflects core disturbance (microcracking). Because sediment velocities are sensitive to confining stress, the velocity vs. void ratio trend will need to be established with samples under load before corrections can be applied to shipboard data. 

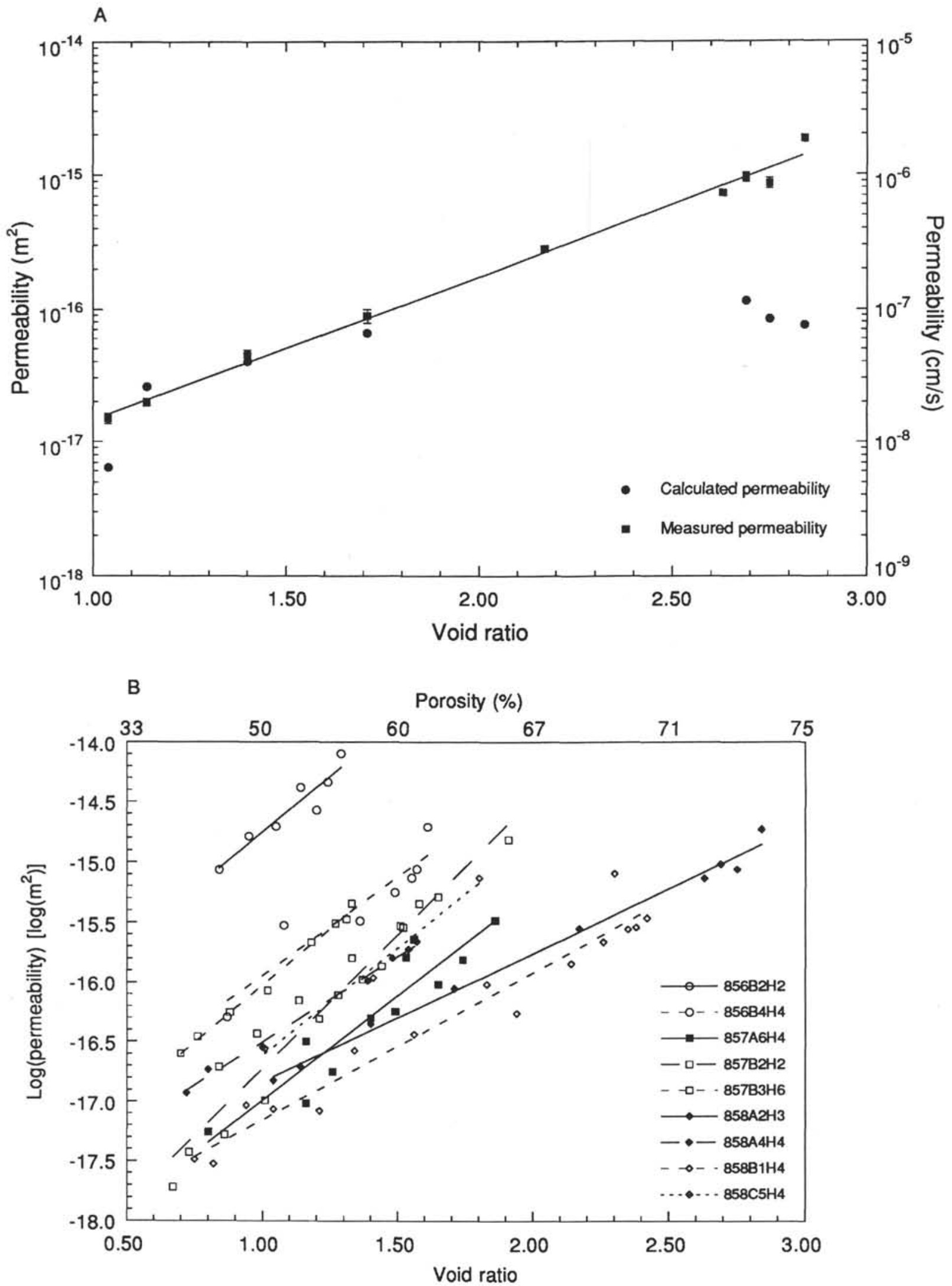

Figure 5. Permeability vs. void ratio relationships for Leg 139 samples. A. Results for Sample 858A-2H-3, 135-141 cm. Calculated permeabilities are from consolidation theory. Measured permeabilities are averages of 6 or more flow tests at each consolidation step. The bars around the measurement data indicate one standard deviation of permeabilities determined at all flow rates. B. All Leg 139 sediment permeability data plotted vs. void ratio. Porosity scale is shown across the top of the plot for reference. 
define cumulative hydraulic impedance, $I(z)$, in a way analogous to thermal resistance (Bullard, 1939; Becker and Von Herzen, 1983),

$$
I(z)=\int_{0}^{z_{1}} \frac{d z}{k(z)}
$$

where $k(z)$ is permeability expressed as a function of depth. We calculated a least-squares best-fit between $\log (k)$ (as estimated with $P I$ ) and depth for each of the Leg 139 drill holes (Fig. 6). This results in the formulation of a $\log (k)=a_{i}+b_{i} \mathrm{z}$ function for each hole, $i$, which can be combined with equation (5) to produce a final algebraic expression for cumulative hydraulic resistance,

$$
I(z)=\frac{\left(1-10^{-b_{i} z}\right)}{\left(2.303 b_{i} 10^{a_{i}}\right)}
$$

The results of these calculations are also presented in Figure 6. This method was applied to samples from all holes for which grain-size and physical properties data were available, even those from Hole $856 \mathrm{~B}$, as the anomalous consolidation and permeability behaviors observed in Sample 856B-2H-2 were not manifest in Sample 856B$4 \mathrm{H}-4$. Figure 6 also includes in-situ permeability values for the samples tested as part of this study, illustrating that the indices and transforms described earlier (from porosity, clay content, and heat flow) for sample rebound and permeability are reasonable.

\section{MICROFABRIC ANALYSES}

Some understanding of the relationships between sediment structure and geotechnical and hydrogeological properties is afforded through examination of sediment microfabrics both before and after consolidation/permeability testing. All the samples we tested were relatively homogeneous parts of a heterogeneous sequence. Our fabric work is still in progress, so only a few qualitative results are described herein. All TEM images ( $\mathrm{Pl} .1)$ are from unconsolidated samples, in a plane parallel to the long axis of the core (and the fluid flow direction induced later through permeability testing). A more detailed analysis of Leg 139 sediment fabrics is presented by Fischer et al. (this volume), and additional results will be published elsewhere.

Plate 1, Figure 1 illustrates the fabric typical of Sample 857B-2H2 prior to consolidation. The sample looks similar to the North Pacific red clay samples of Bryant and Bennett (1988), with common fractured illite particles and aggregates of wispy, amorphous smectite. The sample also apparently contains a significant quartz and feldspar component, in general agreement with shipboard and shore-based analyses (Shipboard Scientific Party, 1992c; W.H. Busch, pers. comm., 1992). This sample exhibited the greatest permeability loss $(\Delta \log [k] /$ $\Delta e=2.3$ ) during consolidation testing of all the Leg 139 samples, consistent with its relatively high smectite content (Fig. 5b). We consider this sample as a "reference" to which the properties and microfabrics of other samples can be compared.

Sample 858A-2H-3 exhibited the smallest reduction in permeability with increasing consolidation, $(\Delta \log [k] / \Delta e=1.1)$. This result is at first surprising, as Sample $858 \mathrm{~B}-2 \mathrm{H}-3$ has a higher clay-size content than Sample 857B-2H-2. But a comparison of microfabric (PI. 1, Fig. 2) suggests that Sample 858A-2H-3 contains numerous recrystallized biogenic particles that may have been resistant to porosity reduction during consolidation. The presence of these particles may also explain why Sample 858A-2H-3 had such a high original water content prior to consolidation (Table 1).

Sample 858B-1H-4 originated from the area of highest heat flow cored during Leg 139. The apparently high in-situ temperature of the sample is reflected in the low smectite content (PI. 1, Fig. 3; W.H. Busch, pers. comm., 1992), despite smectite being common in samples from just a few meters shallower (Shipboard Scientific Party, 1992a). The permeability of this sample was relatively low, despite the lack of smectite, which possibly reflects dense particle packing and diagenetic infilling of porosity (Pl. 1, Fig. 3). The TEM image also reveals small amounts of disseminated sulfide, and possibly several small calcite nodules, both of which were found commonly during sample preparation.

Sample $856 \mathrm{~B}-2 \mathrm{H}-2$ was anomalous in several ways, having the highest permeability (by several orders of magnitude; Fig. 5B) and one of the lowest rebound slopes of all samples tested (Table 2), despite coming from a location of moderate heat flow (within the context of Leg 139 sites) and having a fairly high content of clay-sized particles (Table 1). The microfabric of this sample suggests that it contains few true clay mineral particles. Instead, the sample appears to be composed largely of quartz, feldspar, aggregates of small $(<1 \mu \mathrm{m})$ lath-shaped crystals, possibly disseminated sulfide, and little smectite (Pl. 1, Fig. 4; Shipboard Scientific Party, 1992b). In addition, the TEM image of this sample reveals significantly larger voids than in other samples from similar depths.

\section{DISCUSSION AND CONCLUSIONS}

The hydraulic impedance of the sediment column influences both fluid flow velocities and the rate at which transient pressure gradients within the sediments can dissipate. Continuous coarse-grained units extending across the valley may improve lateral hydraulic communication, but the extent to which these layers will dominate fluid flow geometries is tempered somewhat by the large horizontal scale of the valley. Fluid tends to flow from places of high excess pore pressure (above hydrostatic) to places of low excess pore pressure, but it also tends to travel in a direction containing a component of this pressuregradient vector along the path of greatest conductance (least resistance). If there is greater conductance along a vertical path through the sediments (perhaps of lower permeability, but having a shorter path length) compared to a lateral path through the sediments, fluid may flow vertically, as the seafloor is a surface of zero excess pore pressure.

There is broad evidence for lateral fluid flow through the sediments at Site 857 (Shipboard Scientific Party, 1992c), but it is unclear how this flow relates to active high-temperature venting to the north. Middle Valley probably contains several different scales of hydrothermal circulation (temperatures, velocities, durations), and as in Guaymas Basin (Gieskes et al., 1982), the sediments of Middle Valley may help to keep these systems distinct. Hubbert (1953) demonstrated that flowing fluids are refracted at the interface between zones of differing permeabilities, much like sound is refracted at an interface of sediments having different acoustic velocities, when the net velocity vector is at an angle $<90^{\circ}$ to the interface. Within portions of the sedimentary section that are isolated from high-temperature venting (probably the majority of the seafloor in Middle Valley at any one time), lateral permeability variations in the sediments should strongly influence fluid flow (and heat flow) patterns.

The estimates of permeability and hydraulic impedance in Figure 6 have implications for the hydrogeology of Middle Valley sediments. There is an apparent inverse correlation between heat flow and permeability. For example, the predicted decrease in permeability with depth in Holes $857 \mathrm{~A}$ and $857 \mathrm{~B}$ is moderate compared to that at higher heat flow sites. Similarly, the estimated impedance increases more rapidly with depth at (higher heat flow) Hole 856B than at Holes 857A and $\mathrm{B}$. The variations in estimated permeability and hydraulic impedance within different holes at Site 858 also correlate with heat flow and proximity to high-temperature hydrothermal vents. Holes $858 \mathrm{~B}$ and $858 \mathrm{D}$ were drilled into zones of extremely high heat flow $\left(\sim 11 \mathrm{~W} / \mathrm{m}^{2}\right)$, probably within $10 \mathrm{~m}$ of active vents, but where the thermal gradient appears to be conductive to the depth extent of the direct sediment temperature measurements (Shipboard Scientific Party, 1992d). While heat must be advected vertically below Site 858 to elevate temperatures at shallow depths, the sediment temperatures measured in-situ during Leg 139 seem to document processes within a conductive lid to 


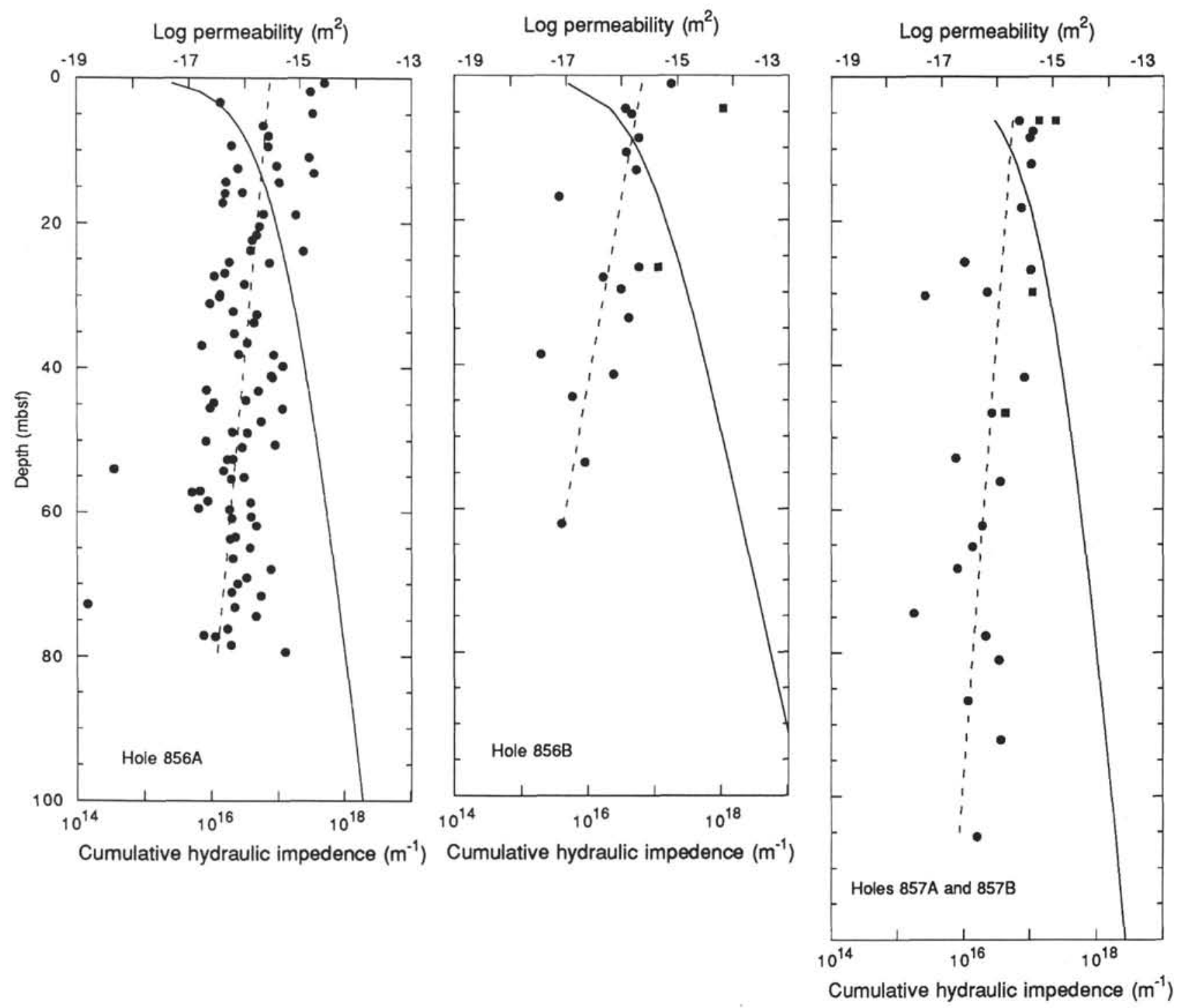

Figure 6. Calculated and measured permeabilities and hydraulic impedance at calculated in-situ conditions for the shallow Leg 139 sediments. Circles are calculated permeabilities based on empirical consolidation and permeability indices, which relate geotechnical and hydrogeological properties to grain size, porosity, and local heat flow. See text and Figure 3 for additional information. Squares are permeabilities determined directly from laboratory measurements, when samples were returned to in-situ conditions in the odometer. The good fit between estimated and measured permeabilities suggests that the relationships defined in this paper can be generally applied. The dotted straight lines are least-squares best fits to the estimated permeability vs. depth data. The solid curves indicate cumulative hydraulic impedance, calculated from the permeability vs. depth functions, using equations (5) and (6) as explained in the text. 

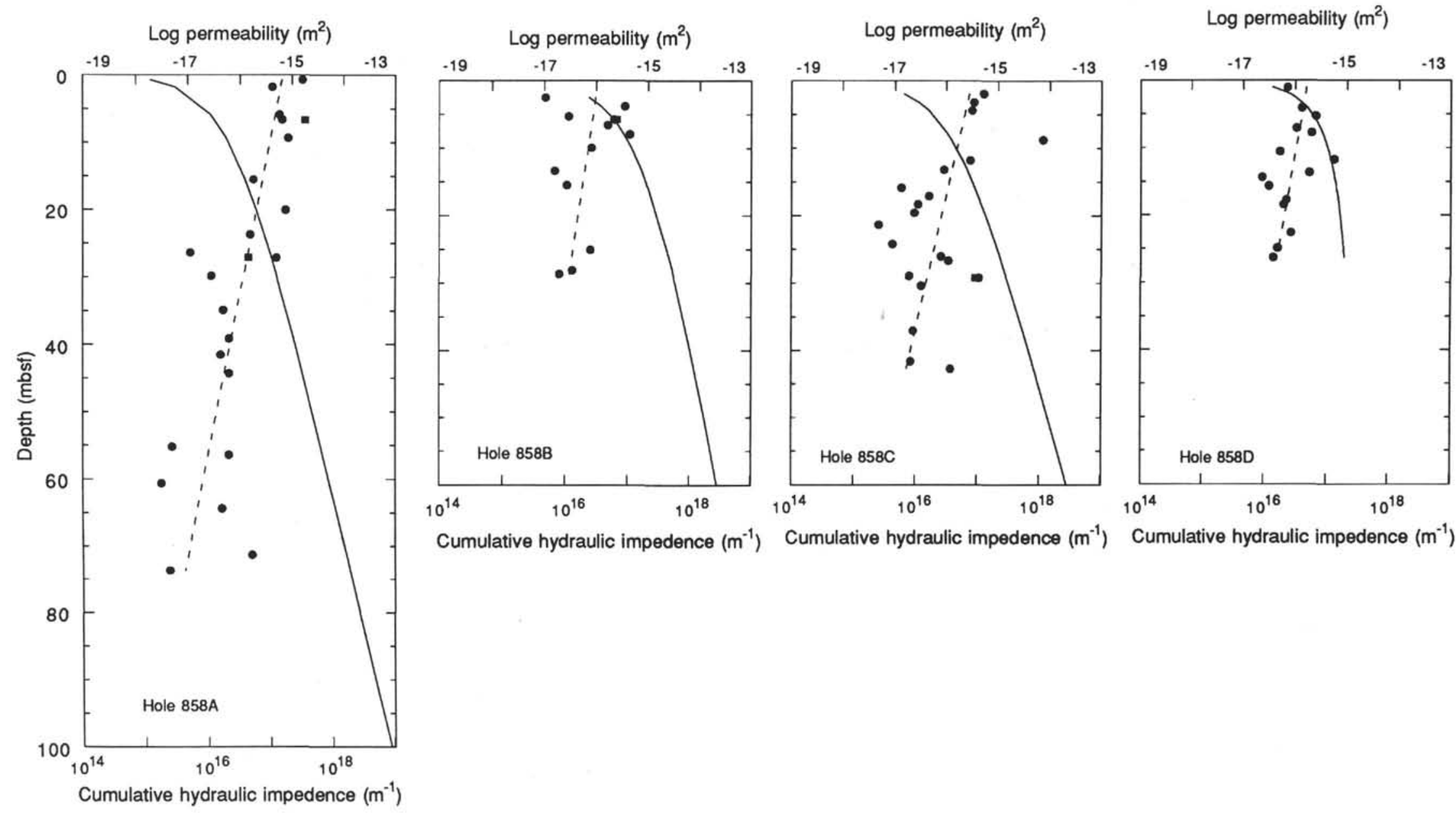

Cumulative hydraulic impedence $\left(\mathrm{m}^{-1}\right)$

Cumulative hydraulic impedence $\left(\mathrm{m}^{-1}\right)$

Figure 6 (continued) 
an underlying convective system. Estimated permeability near the seafloor is lowest at Holes $858 \mathrm{~B}$ and $858 \mathrm{D}$, and the decrease in permeability with depth is extreme, resulting in the steepest hydraulic impedance vs. depth curves. Unfortunately, piston coring penetrated only the upper 30 mbsf in Holes $858 \mathrm{~B}$ and $858 \mathrm{D}$, terminating at a hard (diagenetic?) boundary, so it is not possible to determine whether shallow permeability trends continue at greater depths. Measured heat flow was progressively lower, and estimated permeability progressively higher, in Holes $858 \mathrm{C}$ and $858 \mathrm{~A}$, which are located farther from active vents.

One obvious question that cannot be resolved from the data presented here is which came first, high conductive heat flow and localized venting or lower sediment permeability? It is tempting to speculate that the proximity of a local hydrothermal source of heat and mobile ions and compounds, a function of site location with respect to an underlying intrusion or magma supply, accelerated diagenesis within the sediment column and reduced sediment permeability. It is also possible that initially low permeability and a purely conductive thermal gradient at some sites led the formation of local flow channels through the sediment column, perhaps due to the formation of elevated temperatures and pore pressures at depth, resulting in fracturing or other modification of deeper, semilithified sediments. Initially lower permeabilities could have allowed pore pressures to be raised, leading to hydrofracturing of the sedimentary section. One diagenetic result of higher temperatures close to hydrothermal vents is a loss of smectite at shallow depths (e.g., Shipboard Scientific Party, 1992d). In the absence of additional processes, a reduction in smectite content would be expected to increase permeability. The replacement of smectite with hydrothermal clays, and the precipitation of cements, calcite nodules, anhydrite, and disseminated sulfide appears to counter this trend, however.

The measured and estimated permeabilities presented here are most likely several orders of magnitude lower than bulk permeabilities within basement and within the sediment-sill complex (Becker et al., this volume). The low-permeability cap of sediments is an important component of the surrounding hydrothermal system, for if fluid could circulate freely through the seafloor everywhere at Middle Valley, the deep-lying heat sources would be quenched more quickly. Sediments in this setting thus contribute to the longevity of hydrothermal activity, and may also influence the formation of massive sulfide deposits. It was initially surprising that the massive sulfide drilled at Site 856 appeared to be chemically distinct from the surrounding sediments in which it was hosted (Shipboard Scientific Party, 1992b); our studies of sediment hydrogeology may help to explain this finding. If the bulk-sediment properties are such that fluid cannot circulate freely, hydrothermal flow through the sediment column will be confined to a small number of narrow, highly permeable conduits. Fluid flow through a conduit will initially allow interaction with the surrounding sediments, but as the sediments along the walls of the conduit become altered (and even more impermeable, as proximity to hydrothermal activity seems to be associated with a reduction in permeability) the fluid in the conduit will become progressively more geochemically isolated.

\section{ACKNOWLEDGMENTS}

We wish to thank the Captain, crew, drillers, and ODP technical support staff from Leg 139 for their assistance in recovering the materials used in this study. Salil Kumar assisted with grain-size analyses. Sudha Thimmaraju provided programming support. Bill Busch conducted bulk XRD analyses on whole-round residues. This research was supported by funds from the Ocean Drilling Program and the U.S. Science Support Program (project 8119). Acknowledgment is also made to the Donors of the Petroleum Research Fund, administered by the American Chemical Society, for partial support of this research. Participation of NRL scientists in this research was made possible through NRL funding provided by Dr. H.C. Eppert, Jr., Program Manager, Program Element Number $0601153 \mathrm{~N}$. This manuscript was improved through thoughtful reviews by Earl Davis, Peter Holler, and Elliott Taylor.

\section{REFERENCES ${ }^{*}$}

Becker, K., and Von Herzen, R.P., 1983. Heat transfer through the sediments of the Mounds Hydrothermal area, Galapagos Spreading Center at $86^{\circ} \mathrm{W}$. J. Geophys. Res., 88:995-1008.

Bishop, A.W., and Henkel, D.J., 1962. The Measurement of Soil Properties in the Triaxial Test (2nd ed.): London (Edward Arnold).

Bryant, W.R., and Bennett, R.H., 1988. Origin, physical and mineralogical nature of red clays: the Pacific ocean as a model. Geo-Mar. Lett., 8:189-249.

Bryant, W., Wetzel, A., Taylor, E., and Sweet, W., 1986. Consolidation characteristics and permeability of Mississippi Fan sediments. In Bouma, A.H., Coleman, J.M., Meyer, A.W., et al., Init. Repts. DSDP, 96: Washington (U.S. Govt. Printing Office), 797-809.

Bullard, E.C., 1939. Heat flow in South Africa. Proc. R. Soc. London A, 173:474-502.

Busch, W.H., 1989. Patterns of sediment compaction at Ocean Drilling Program Sites 645, 646, and 647, Baffin Bay and Labrador Sea. In Srivastava, S.P., Arthur, M.A., Clement, B., et al., Proc. ODP, Sci. Results, 105: College Station, Texas (Ocean Drilling Program), 781-790.

Casagrande, A., 1936. Determination of preconsolidation load and its practical significance. Proc. Ist Conf. Soil Mech. and Found. Eng. (Vol. 3). Am. Soc. Civ. Eng., 60-64.

Davis, E.E., Becker, K., Pettigrew, T., Carson, B., and MacDonald, R., 1992. CORK: a hydrologic seal and downhole observatory for deep-ocean boreholes. In Davis, E.E., Mottl, M.J., Fisher, A.T., et al., Proc. ODP, Init. Repts., 139: College Station, TX (Ocean Drilling Program), 43-53.

Davis, E.E., Mottl, M.J., Fisher, A.T., et al., 1992. Proc. ODP, Init. Repts., 139: College Station, TX (Ocean Drilling Program).

Fisher, A., and Narasimhan, T.N., 1991. Sill intrusion in a buried spreading center: a numerical study of early rifting processes at a passive margin. Earth Planet. Sci. Lett., 103:100-115.

Folk, R.L., 1974. Petrology of Sedimentary Rocks: Austin (Hemphill Publ.)

Gieskes, J.M., Kastner, M., Einsele, G., Kelts, K., and Niemitz, J., 1982. Hydrothermal activity in the Guaymas Basin, Gulf of California: a synthesis. In Curray, J.R., Moore, D.G., et al., Init. Repts. DSDP, 64: Washington (U.S. Govt. Printing Office), 1159-1168.

Hamilton, E.L., 1976. Variations of density and porosity with depth in deep-sea sediments. J. Sediment. Petrol., 46:280-300.

Hubbert, M.K., 1953. Entrapment of petroleum under hydrodynamic conditions. AAPG Bull., 37:1954-2026.

Lambe, T.W., and Whitman, R.V., 1969. Soil Testing for Engineers: New York (Wiley).

Lowe, J., Zaccheo, P.F., and Feldman, H.S., 1964. Consolidation testing with back pressure. J. Geotech. Eng. Div., Am. Soc. Civ. Eng., 90:69-86.

Mitchell, J.K., 1986. Practical problems from surprising soil behavior. $J$. Geotech. Eng., 112:259-289.

Olsen, H.W., Nichols, R.W., and Rice, T.C., 1985. Low gradient permeability measurements in a triaxial system. Geotechnique, 35:145-157.

Sen, P.N., Straley, C., Kenyon, W.E., and Whittingham, M.S., 1990. Surfaceto-volume ratio, charge density, nuclear magnetic relaxation, and permeability in clay-bearing sandstones. Geophysics, 55:61-69.

Shipboard Scientific Party, 1992a. Site 855. In Davis, E.E., Mottl, M.J., Fisher, A.T., et al., Proc. ODP, Init. Repts., 139: College Station, TX (Ocean Drilling Program), 101-160.

, 1992b. Site 856. In Davis, E.E., Mottl, M.J., Fisher, A.T., et al., Proc. ODP, Init. Repts., 139: College Station, TX (Ocean Drilling Program), 161-281.

, 1992c. Site 857. In Davis, E.E., Mottl, M.J., Fisher, A.T., et al., Proc. ODP, Init. Repts., 139: College Station, TX (Ocean Drilling Program), 283-429.

, 1992d. Site 858. In Davis, E.E., Mottl, M.J., Fisher, A.T., et al., Proc. ODP, Init. Repts., 139: College Station, TX (Ocean Drilling Program), 431-569.

Wood, D.M., 1990. Soil Behavior and Critical State Soil Mechanics: Cambridge (Cambridge Univ. Press).

\footnotetext{
-Abbreviations for names of organizations and publications in ODP reference lists follow the style given in Chemical Abstracts Service Source Index (published by American Chemical Society).
}

\footnotetext{
Date of initial receipt: 21 December 1992

Date of acceptance: 2 June 1993

Ms 139SR-246
} 

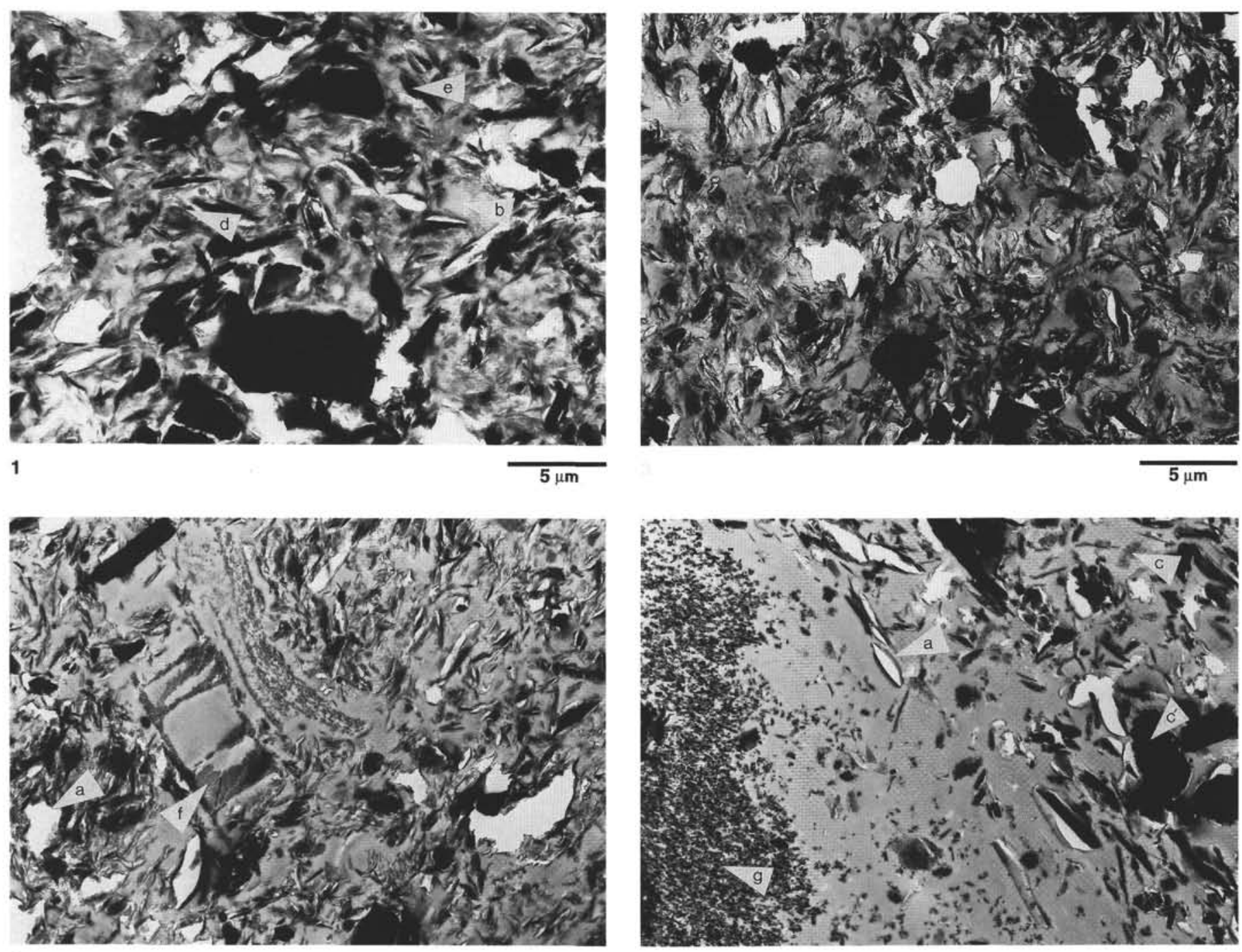

2
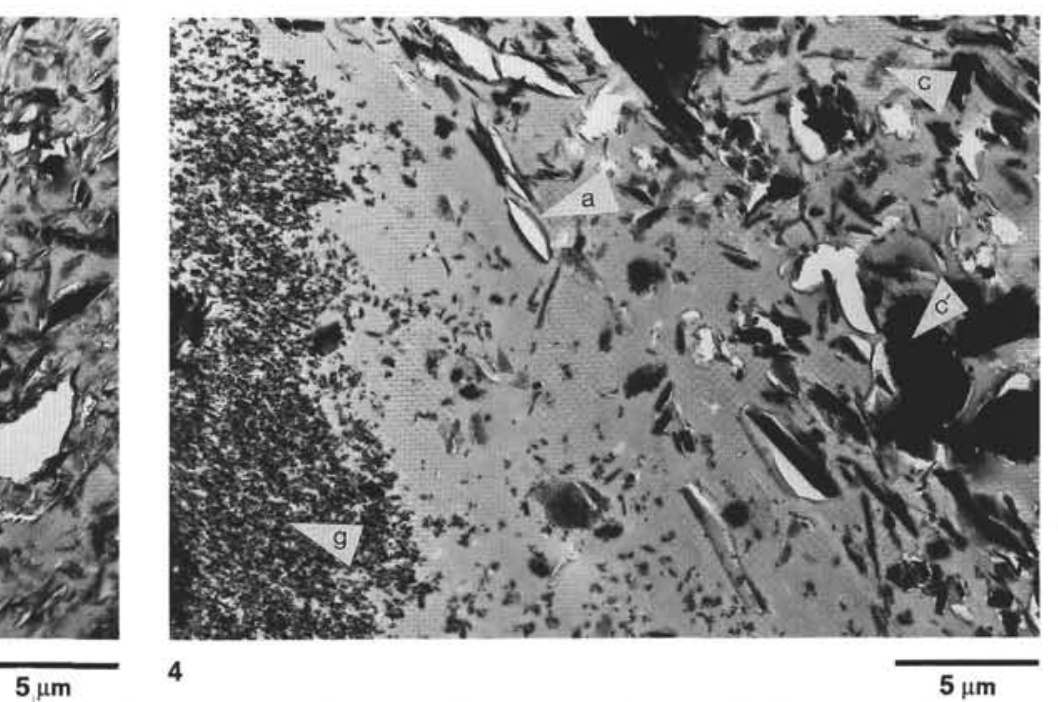

Plate 1. Transmission electron microscopy images of selected Leg 139 consolidation/permeability samples, from subsamples collected prior to testing. All images are $11,000 \times$ magnification and are oriented in a plane that is parallel to the long axis of the cores and to the direction of forced fluid flow during later permeability testing. Open (white) spaces, labeled a, are artifacts (where grains have been plucked from the sample or where a tear has been made in the ultrathin section). Light areas of pure resin are actual sample voids (labeled b). Particles with the greatest density appear darker than others (compare particles labeled c and c'). Fine, wispy particles are smectite (labeled d), while more massive, platy particles are illite or other clay (labeled e). 1. Sample 857B-2H-2, 6.1 mbsf. 2. Sample 858A-2H-3, $6.7 \mathrm{mbsf}$. Note recrystallized test on the left side of the image (f). 3. Sample 858B-1H-4, 5.8 mbsf. 4. Sample $856 \mathrm{~B}-2 \mathrm{H}-2,4.5 \mathrm{mbsf}$. The fine particles on the left side of this image may be disseminated sulfide $(\mathrm{g})$. 


\section{APPENDIX: LABORATORY METHODS AND RESULTS OF GRAIN-SIZE ANALYSES OF LEG 139 PHYSICAL PROPERTIES RESIDUES}

\section{GEOTECHNICAL AND HYDROGEOLOGICAL TESTS}

Samples were cut from the ends of individual core sections using a liner knife and spatula. The cut whole-round samples were then capped (without acetone), labeled and oriented, and sealed with electrical tape. The sealed samples were dipped repeatedly in warm wax (a 50\% mixture of beeswax and paraffin) and stored upright in a shipboard core refrigerator at $10^{\circ}-15^{\circ} \mathrm{C}$ for the duration of the cruise. At the end of the cruise, the samples were shipped upright to Texas A\&M University in a refrigerated container, and transferred to $100 \%$ humidity, cold storage at the ODP facility. This combination of wax coating and upright storage in a cold (but not freezing) and humid environment should have stabilized material properties and overall composition for the duration of the hydrogeological tests (Mitchell, 1986). Some whole-round subsamples were sent to the Naval Research Laboratory (NRL) for separate testing; these samples were also $\mathrm{x}$-rayed prior to testing.

Samples were consolidated at TAMU following the American Society of Testing Materials method D2435-80 as modified by Lowe et al. (1964), using a one-dimensional oedometer with independent back-pressure and pore-pressure controls. Test subsamples were extruded and cut from whole-round core samples using a cylindrical cutting ring, then extruded into a brass floating ring. Each test sample was $50.3 \mathrm{~mm}$ in diameter and initially $14-16 \mathrm{~mm}$ thick. Residue from sample preparation was collected at this stage for water-content, average grain-density, grain-size, bulk XRD, and TEM analyses. The samples were sandwiched between Whatman \#54 filter papers and porous stones, placed in a Rowe cell, and back pressured gradually to $500 \mathrm{kPa}$. Each sample was left fully back-pressured (but with minimal effective stress) for $24 \mathrm{hr}$ to ensure complete saturation and dissolution of air bubbles in the pressure lines. Back, pore, and axial pressures were controlled independently with digital controllers; these instruments can be computer controlled but were operated manually for the experiments reported here.

After back pressuring, samples were consolidated under increasing (generally doubled) loads of roughly $10-2300 \mathrm{kPa}$ effective stress (510-2800 kPa axial stress and $500 \mathrm{kPa}$ pore/back pressure). Consolidation data were logged continuously using a Schaevitz linear voltage displacement transducer (LVDT, model GCD-121-500) having a digital resolution better than $0.001 \mathrm{~mm}$ and linearity of $0.07 \%$. Consolidation was allowed at each step for $12-24 \mathrm{hr}$ (with less time required at early stages of consolidation and for rebound), with each test lasting about two weeks.

Permeabilities were determined for each TAMU sample at the end of every sediment consolidation step using a Harvard Apparatus medical flow pump as described by Olsen et al. (1985). A constant volume flux was forced to flow through the sample (via back-pressure and pore-pressure ports), and the differential pressure was monitored with a Valadyne 300D differential pressure transducer. Several flow rates were used in each direction, and permeability was calculated directly using Darcy's law to relate head gradient, $i$, and flow rate, $f$ (i.e., $f=-\kappa i$, where $\kappa$ is permeability in units of $\mathrm{L} / \mathrm{T}$ ). This method allowed the application of extremely low heads (often less than 10) across the samples, reducing the risk of disturbance during testing. Sediment permeabilities were also calculated (along with consolidation coefficients) from the form of individual-step consolidation curves, using the standard methods outlined in Lambe and Whitman (1969). Calculating these permeabilities required identification of primary and secondary consolidation trends, which was often hampered because these samples tended to undergo primary consolidation rapidly, often in the first 15-30 s. In addition, consolidation theory applies to idealized homogeneous samples rather than the heterogeneous samples tested here. Calculated permeability values tended to fall an order of magnitude or more below permeabilities measured directly, and thus should be viewed with some caution.

Additional consolidation tests were performed with a modified Wykeham Farrance triaxial compression system which loads samples uniformally in all three dimensions and allows for the measurement of permeabilities and acoustic velocities after each consolidation step. Permeability was measured in this equipment using a pore-pressure decay technique (Bishop and Henkel, 1962). Compressional and shear wave velocities were measured using transducers mounted in the end caps at the top and bottom of the samples, i.e., velocities were measured parallel to the long axis of the cores. An initial series of tests was conducted at the University North College of Wales at Manai Bridge; similar tests were later conducted at the Naval Research Laboratory (NRL), Stennis Space Center. Permeabilities there were determined with a constant head apparatus. The three samples tested in Wales were consolidated on a system that did not permit measurement of sample height during consolidation.
Consequently, only initial and final sample heights were determined, permitting accurate determination of acoustic velocities and permeabilities only at the start and end of each consolidation run. Tests at the NRL included sample height determinations throughout each consolidation run. Results of the Wales and NRL testing were not available in time for inclusion in this paper and will be reported elsewhere.

\section{TRANSMISSION ELECTRON MICROSCOPY}

Subsamples were collected for TEM analysis both before and after consolidation testing. In both cases, samples were cut such that TEM images would be in planes parallel and perpendicular to the long axis of the cores. These directions are also parallel and perpendicular, respectively, to the direction of fluid flow during permeability testing. Subsamples collected prior to consolidation testing were taken from the residue immediately adjacent to the section of the whole round that was placed in the oedometer; subsamples taken after consolidation/permeability testing were cut from the sample itself. The subsamples were all cut with a straight razor in rectangular prisms of $2 \times 2 \times$ $8 \mathrm{~mm}$. These prisms were dehydrated using the ethyl alcohol replacement technique, with steps at $30 \%, 50 \%, 70 \%, 90 \%$, and $100 \%$ alcohol each taking $30 \mathrm{~min}$. The sediment prisms were then transferred to a $100 \%$ alcohol solution for $24 \mathrm{hr}$. The absence of residual pore water at this stage was confirmed with the silver nitrate test.

The sediment prisms were then impregnated with LR White acrylic resin (London Resin Co., Ltd.) at 50\%, 75\%, and $100 \%$ concentrations in ethyl alcohol, with each step lasting $30 \mathrm{~min}$, then transferred into $100 \%$ LR White resin for $24 \mathrm{hr}$. Impregnated materials were then placed in a polyethylene capsule, which was sealed to eliminate exchange with air, and cured at $60^{\circ} \mathrm{C}$ for $24 \mathrm{hr}$. The top of each dry capsule was cut into a $0.2 \times 0.2 \times 0.2 \mathrm{~mm}$ block with a razor, and ultrathin sectioned to $1000 \AA$ with a microtome. Each ultrathin section was picked up with a copper grid and coated lightly with carbon in a vacuum evaporator. The ultrathin sections were then examined under a Zeiss 10 transmission electron microscope at the TAMU Electron Microscopy Center.

\section{GRAIN-SIZE SEPARATIONS}

The main objectives of grain-size separations were (1) to determine accurately the weight percentages of sand, silt, and clay in the residues from Leg 139 physical properties samples; and (2) to separate a sufficient clay fraction for XRD analyses. We processed about 300 samples in a period of 20 weeks. The analytical method was adapted from Folk (1974), as modified by our ongoing experience with the Leg 139 samples, and with the advice of several sedimentologists. We defined the boundary between sand and silt at $63 \mu \mathrm{m}$, and the boundary between silt and clay at $4 \mu \mathrm{m}$. Some samples could not be tested, either because there was insufficient residue $(<10 \mathrm{~g})$ or because the samples would not disaggregate.

\section{Determination of Weight Percentages of Sand, Silt, and Clay}

1. Freeze dry the samples for $48-96 \mathrm{hr}$ to remove intergranular moisture. (We dried about 30-40 samples at a time, then stored the dried samples in desiccators until we were ready to process them.)

2. Label and weigh an appropriate number of evaporating dishes (we processed 4-10 samples at a time). Place $10-20 \mathrm{~g}$ of dried sample in a labeled dish, and record the combined weight (sample + dish). Calculate the sample weight by correcting for salt content (based on shipboard water content; see the following). Add enough $4 \mathrm{~g} / \mathrm{L}$ Calgon (hexametaphosphate) and water solution to cover the sample, and cover the dish with parafilm or a watch glass. Allow the covered samples to sit for at least several hours to begin disaggregation.

3. If the sample does not disaggregate overnight, "help" it along with a brush or gloved finger or by sonification. Put each sample through a $63-\mu \mathrm{m}$ sieve to separate the sand component, with the fine fraction running into a clean $400 \mathrm{~mL}$ beaker. After all the clay and silt passes through the mesh, lift the sieve from the beaker and carefully rinse any residue from the bottom of the screen into the beaker with Calgon solution.

4. Rinse the sand remaining in the sieve with distilled water, then wash it into another labeled and preweighed evaporating dish. Allow each dish with sand to sit in a convection oven (preset for $105^{\circ}-110^{\circ} \mathrm{C}$ ) for $24 \mathrm{hr}$ to dry. After $24 \mathrm{hr}$ (or slightly longer, if necessary) remove each dish (with dry sand) and place it in a desiccator to cool. Weigh each dish and calculate the total mass of sand. Note that no salt corrections are needed for the mass of sand; it is assumed that all salt is washed through the mesh by the distilled-water rinse.

5. Use more Calgon solution to wash the contents of each beaker into a bottle, being careful to transfer all silt and clay residue. Be careful not to add too much Calgon solution, as the total volume should be less than about 700 
$\mathrm{mL}$. Close each bottle and shake gently to assist with deflocculation. Allow each silt/clay/Calgon-solution mixture to sit for at least several hours.

6. Pour the silt/clay/water/Calgon-solution mixture into a labeled, clean, $1000 \mathrm{~mL}$ graduated cylinder. Fill the cylinder to the next highest $100 \mathrm{~mL}$ increment (at least $500 \mathrm{~mL}$, but no more than $1000 \mathrm{~mL}$ ) with Calgon solution. Use a stirring rod or small plunger to mix the solution vigorously. At the moment that you stop mixing, start a stopwatch or note the absolute time. Pour some Calgon solution from the main reservoir (prepared well in advance and allowed to thermally equilibrate with the laboratory) into a beaker and measure its temperature. Use the fluid temperature to calculate viscosity, then use Stokes' law to calculate how long to let the sediment settle so that all silt particles fall below some fixed distance from the surface of the fluid in the cylinder (we generally used $10 \mathrm{~cm}$ ).

7. Use a clean $25 \mathrm{~mL}$, bulbed pipette marked at $0.1-\mathrm{mL}$ increments to sample the sediment/fluid mixture in the cylinder at the appropriate time and depth (i.e., $10 \mathrm{~cm}$ below the fluid surface). Lower the pipette into the cylinder to the appropriate depth and draw off about $20 \mathrm{~mL}$ of water and sediment. This sediment is assumed to be entirely clay; i.e., all the silt should have settled below the sampling depth. It is not critical to remove exactly $20 \mathrm{~mL}$, but it is critical to record exactly how much solution is removed (to $\pm 0.1 \mathrm{~mL}$ ). Transfer the clay/Calgon-solution mixture into a labeled, preweighed $100 \mathrm{~mL}$ beaker. Rinse the pipette into the beaker by drawing enough clean Calgon solution into the pipette to clean out any clay residue clinging to the inside walls, and release it into the beaker containing the sample. Record the amount of rinse water drawn and released into the beaker with the sample. Place the beaker in the preheated $\left(105^{\circ}-110^{\circ} \mathrm{C}\right)$ oven for $24 \mathrm{hr}$.

8. After $24 \mathrm{hr}$, remove the beaker from the oven, place it in the desiccator to cool, and then weigh it. The total mass of clay in the dry sample is calculated based on the proportion of fluid sampled with the pipette (relative to the total volume in the cylinder), and corrected for the mass of Calgon in the fluid sample (in both the solution and the rinse water used to get the residue out of the pipette). An additional salt correction is not necessary for the clay fraction, as the salt is diluted in the cylinder. The weight percentage of clay can be calculated by comparing the mass of clay to the mass of the salt-corrected, dry sample.

9. The mass (and weight percent) of the silt fraction is determined by subtracting the masses of sand and clay fractions from the corrected, dry-sample mass.

\section{Separation of Clay for XRD Analysis}

10. Use a stirring rod or plunger to thoroughly mix the clay/silt/Calgonsolution mixture remaining in the graduated cylinder (from Step 6). Pour sufficient mixture into four 100 -mL centrifuge tubes to fill exactly to lines marked near the tops of the tubes. Cap the tubes and place them in a centrifuge.

11. Using Stokes' law and the radial distance from the centrifuge shaft to the center of the test tube, calculate the centrifuge speed and settling time required to settle out particles greater than $4 \mu \mathrm{m}$ in diameter.
12. After the appropriate centrifuge time, remove each tube and decant off most of the fluid. (We decanted $10 \mathrm{~cm}$ of solution from each centrifuge tube [about $65-70 \mathrm{~mL}$ ] with a vacuum line and flask.) This solution contains pure clay and is retained. Repeat this procedure with four more tubes. (At this point, we had separated clay from about $500-800 \mathrm{~mL}$ of solution and suctioned off about $300-500 \mathrm{~mL}$ of mixture containing Calgon solution and clay.) Discard any material remaining in the graduated cylinder.

13. Settle enough of the clay to decant off most of the Calgon solution. Fill four clean centrifuge tubes and centrifuge to settle off all particles $>0.25 \mu \mathrm{m}$ in diameter. (The assumption here is that particles smaller than about $0.25 \mu \mathrm{m}$ have the same composition as particles between 0.25 and $4.0 \mu \mathrm{m}$ in diameter.) The decision to settle particles greater than $0.25 \mu \mathrm{m}$ is somewhat arbitrary, but setting particles with smaller diameters is extremely time consuming.

14. Decant and discard the fluid above the settled clay, add a few milliliters of distilled water to each tube, and break up the settled clay with a stirring rod. Transfer this clay and water solution into small, labeled bottles and seal them.

The entire procedure takes about 2-3 hr/sample, spread out over several days. The Folk (1974) method relies on the particles behaving as ideal spheres settling in a viscous fluid according to Stokes' law. Because the method requires taking a small subsample of the total sample to determine the clay content, i.e., subsampling with the bulbed pipette after some of the silt has settled, it is desirable to have a large mass of material in the cylinder. On the other hand, if one uses too large a sample in the settling tube, then the grains interact with each other. They can actually "drag" each other down; the big particles especially can drag down the small ones, invalidating Stokes' law. After a little experimentation, we generally tried to use $500-700 \mathrm{ml}$ of fluid and $10-20 \mathrm{~g}$ of dry sample.

This method is inappropriate for samples containing a high percentage of organic carbon, as the organics can act as a glue to bind the particles together. Highly organic sediments should first be treated with $\mathrm{H}_{2} \mathrm{O}_{2}$ to decompose the organic material. Most samples from Leg 139 had less than 1\% total organic carbon by weight.

We ran blank tests on our Calgon solution and distilled water to estimate errors introduced during standard corrections, and applied these corrections conservatively. In some cases, however, we ended up with negative clay masses (either because of experimental error or simply because there was so little clay that we were unable to distinguish its presence). Usually these negative values were small (suggesting simply that we were at the limit of detection using this method). In other cases, the sand mass plus calculated clay mass exceeded the original sample mass, probably as a result of experimental errors. We estimate that the percentages of sand, silt, and clay determined with this procedure are good to $\pm 5 \%-10 \%$ (probably closer to $5 \%$ in most cases), based on a test of likely errors and the maximum resolution of our instrumentation. The data that follow are reported in normalized form. The raw data were weight percentages of sand, silt, and clay, including negative values. In the normalized data set, all negative values were set equal to $0 \%$, and the other values were recalculated. 
Table A1. Normalized grain-size data for Leg 139 physical-properties residues.

\begin{tabular}{|c|c|c|c|c|}
\hline \multirow{2}{*}{$\begin{array}{l}\text { Core, section, } \\
\text { interval }(\mathrm{cm})\end{array}$} & \multirow{2}{*}{$\begin{array}{l}\text { Depth } \\
\text { (mbsf) }\end{array}$} & \multicolumn{3}{|c|}{$\begin{array}{c}\text { Normalized } \\
\text { dry weight }{ }^{\mathrm{b}}(\%)\end{array}$} \\
\hline & & Sand & Silt & Clay \\
\hline \multicolumn{5}{|l|}{$139-855 \mathrm{~A}-$} \\
\hline 1R-1, 73-76 & 0.73 & 29.1 & 58.7 & 12.2 \\
\hline IR- $-2,41-43$ & 1.91 & 2.3 & 90.7 & 7.0 \\
\hline $1 R-2,107-109$ & 2.57 & 2.2 & 47.5 & 50.3 \\
\hline $1 R-3,40-43$ & 3.40 & 1.7 & 96.6 & 1.7 \\
\hline $1 \mathrm{R}-3,108-111$ & 4.08 & 14.7 & 37.3 & 48.0 \\
\hline $1 R-4,41-43$ & 4.91 & 3.1 & 97.0 & - \\
\hline 1R-4, 107-109 & 5.57 & 1.0 & 99.1 & - \\
\hline 1R-5, 41- 44 & 6.41 & 3.4 & 80.7 & 15.9 \\
\hline $2 \mathrm{R}-1,41-44$ & 8.01 & 2.7 & 87.2 & 10.2 \\
\hline $2 \mathrm{R}-1,110-113$ & 8.70 & 21.2 & 76.7 & 2.1 \\
\hline $2 \mathrm{R}-2,37-40$ & 9.47 & 4.3 & 32.3 & 63.4 \\
\hline $2 \mathrm{R}-2,110-113$ & 10.20 & 0.6 & 95.5 & 3.9 \\
\hline $2 \mathrm{R}-3,37-40$ & 10.97 & 0.5 & 99.5 & - \\
\hline $2 \mathrm{R}-4,41-44$ & 12.51 & 14.3 & 28.1 & 57.6 \\
\hline $2 \mathrm{R}-4,107-110$ & 13.17 & 13.5 & 86.5 & - \\
\hline $2 \mathrm{R}-5,38-41$ & 13.98 & 4.7 & 87.2 & 8.1 \\
\hline $2 \mathrm{R}-5,85-88$ & 14.45 & 5.1 & 79.3 & 15.6 \\
\hline $3 R-1,40-43$ & 17.00 & 7.7 & 21.3 & 70.9 \\
\hline $3 \mathrm{R}-1,108-111$ & 17.68 & 12.7 & 87.3 & - \\
\hline $3 R-2,41-44$ & 18.51 & 4.0 & 82.8 & 13.2 \\
\hline $3 \mathrm{R}-2,110-113$ & 19.20 & 2.2 & 84.9 & 12.9 \\
\hline $3 R-3,40-43$ & 20.00 & 0.4 & 88.2 & 11.4 \\
\hline $3 R-3,110-113$ & 20.70 & 0.7 & 85.7 & 13.6 \\
\hline $4 \mathrm{R}-1,38-40$ & 26.38 & 0.6 & 88.0 & 11.4 \\
\hline $4 \mathrm{R}-1,101-104$ & 27.01 & 3.1 & 89.9 & 7.1 \\
\hline $4 \mathrm{R}-2,37-40$ & 27.87 & 11.2 & 23.9 & 64.9 \\
\hline $4 \mathrm{R}-2,108-111$ & 28.58 & 3.3 & 88.8 & 7.8 \\
\hline $4 R-3,39-41$ & 29.39 & 13.1 & 61.7 & 25.2 \\
\hline $4 \mathrm{R}-3,107-110$ & 30.07 & 1.6 & 92.0 & 6.4 \\
\hline $4 R-4,38-41$ & 30.88 & 2.3 & 51.2 & 46.5 \\
\hline $5 \mathrm{R}-1,36-39$ & 35.86 & 34.6 & 31.9 & 33.6 \\
\hline $5 \mathrm{R}-1,106-109$ & 36.56 & 2.1 & 45.9 & 52.0 \\
\hline $5 R-2,34-37$ & 37.34 & 48.4 & 28.9 & 22.8 \\
\hline $6 \mathrm{R}-1,37-41$ & 45.87 & 0.2 & 99.8 & - \\
\hline $6 \mathrm{R}-1,109-112$ & 46.59 & 0.4 & 99.7 & - \\
\hline $6 \mathrm{R}-2,17-21$ & 47.17 & 0.6 & 92.6 & 6.8 \\
\hline $7 \mathrm{R}-1,37-41$ & 55.47 & 27.0 & 56.3 & 16.7 \\
\hline $7 \mathrm{R}-1,108-112$ & 56.18 & 63.8 & 36.2 & - \\
\hline $7 R-2,39-43$ & 56.99 & 37.5 & 47.1 & 15.3 \\
\hline $7 \mathrm{R}-2,108-112$ & 57.68 & 0.8 & 99.2 & - \\
\hline $7 R-3,36-40$ & 58.46 & 3.9 & 96.1 & - \\
\hline 139-855B- & & & & \\
\hline $2 \mathrm{R}-1,70-72$ & 6.38 & 0.0 & 95.0 & 5.0 \\
\hline $2 \mathrm{R}-2,70-72$ & 7.88 & 10.6 & - & 89.5 \\
\hline $4 R-1,68-72$ & 25.18 & 34.5 & 35.6 & 29.9 \\
\hline $4 \mathrm{R}-2,68-72$ & 26.68 & 2.0 & 22.7 & 75.3 \\
\hline $4 \mathrm{R}-3,68-72$ & 28.18 & 0.6 & 37.7 & 61.6 \\
\hline $4 R-4,68-72$ & 29.68 & 2.2 & 97.8 & - \\
\hline $4 \mathrm{R}-5,68-72$ & 31.18 & 6.8 & 24.8 & 68.4 \\
\hline 139-855C- & & & & \\
\hline $1 \mathrm{R}-1,68-72$ & 0.68 & 2.5 & - & 97.5 \\
\hline IR-2, 69-71 & 2,19 & 1.3 & 16.2 & 82.5 \\
\hline IR-3, 68-70 & 3.68 & 1.0 & 98.7 & 0.3 \\
\hline $1 R-4,68-70$ & 5.18 & 2.2 & 46.1 & 51.7 \\
\hline IR-5, 68-70 & 6.68 & 2.3 & 38.6 & 59.1 \\
\hline $2 \mathrm{R}-1,74-76$ & & 0.5 & 20.9 & 78.6 \\
\hline $2 \mathrm{R}-2,65-69$ & 10.85 & 0.6 & 61.7 & 37.7 \\
\hline $2 \mathrm{R}-3,74-78$ & 12.44 & 0.6 & 87.7 & 11.7 \\
\hline $2 R-4,71-75$ & 13.91 & 1.5 & - & 98.5 \\
\hline 2R-5, 65-69 & 15.35 & 3.4 & 96.6 & - \\
\hline $2 \mathrm{R}-6,75-79$ & 16.95 & 0.5 & 35.3 & 64.3 \\
\hline $3 R-1,67-70$ & 18.37 & 15.2 & 4.0 & 80.8 \\
\hline 3R-2, 74-77 & 19.94 & 0.8 & 87.6 & 11.6 \\
\hline $3 R-3,74-77$ & 21.44 & 1.1 & 2.0 & 96.9 \\
\hline $3 R-4,66-69$ & 22.86 & 0.1 & 56.0 & 43.9 \\
\hline $3 R-5,72-75$ & 24.42 & 0.5 & 54.6 & 44.9 \\
\hline 4R-2, 73-75 & 29.33 & 0.1 & 22.2 & 77.7 \\
\hline $4 R-3,66-70$ & 30.76 & 0.6 & 28.7 & 70.7 \\
\hline $6 \mathrm{R}-1,65-67$ & 47.15 & 3.7 & 96.3 & - \\
\hline $6 \mathrm{R}-2,73-77$ & 48.73 & 1.4 & 19.7 & 78.9 \\
\hline 6R-3, 73-77 & 50.23 & 35.0 & 65.0 & - \\
\hline $6 \mathrm{R}-4,73-77$ & 51.73 & 32.9 & 45.9 & 21.2 \\
\hline $6 \mathrm{R}-5,72-76$ & 53.22 & 39.0 & 43.0 & 18.0 \\
\hline $6 \mathrm{R}-6,65-69$ & 54.65 & 1.3 & 56.5 & 42.2 \\
\hline 6R-7, 31-35 & 55.81 & 1.2 & 15.7 & 83.1 \\
\hline $7 R-1,72-76$ & 56.82 & 0.6 & 26.5 & 73.0 \\
\hline $7 \mathrm{R}-2,68-72$ & 58.28 & 0.9 & 75.8 & 23.3 \\
\hline $7 R-3,75-79$ & 59.85 & 1.3 & 60.7 & 38.0 \\
\hline $7 \mathrm{R}-4,74-78$ & 61.34 & 0.7 & 84.5 & 14.8 \\
\hline $7 R-5,66-70$ & 62.76 & 3.5 & 96.5 & - \\
\hline $7 R-6,74-78$ & 64.34 & 6.4 & 35.5 & 58.1 \\
\hline $8 R-1,48-52$ & 66.18 & 1.0 & 17.4 & 81.6 \\
\hline
\end{tabular}

\begin{tabular}{|c|c|c|c|c|}
\hline \multirow{2}{*}{$\begin{array}{l}\text { Core, section, } \\
\text { interval }(\mathrm{cm})\end{array}$} & \multirow{2}{*}{$\begin{array}{l}\text { Deptha } \\
\text { (mbsf) }\end{array}$} & \multicolumn{3}{|c|}{$\begin{array}{c}\text { Normalized } \\
\text { dry weight }{ }^{\mathrm{b}}(\%)\end{array}$} \\
\hline & & Sand & Silt & Clay \\
\hline $8 R-2,37-39$ & 66.82 & 2.9 & 31.0 & 66.1 \\
\hline $10 \mathrm{R}-1,68-72$ & 85.58 & 0.5 & 60.4 & 39.2 \\
\hline $10 R-3,68-72$ & 87.08 & 0.1 & 30.6 & 69.3 \\
\hline $10 \mathrm{R}-4,71-75$ & 88.61 & 0.5 & 28.2 & 71.4 \\
\hline $10 R-5,50-53$ & 89.90 & 0.5 & 49.5 & 50.1 \\
\hline IIR-1, 70-72 & 95.30 & 8.9 & 70.6 & 20.5 \\
\hline $11 \mathrm{R}-2,39-42$ & 96.49 & 13.5 & 79.5 & 7.0 \\
\hline \multicolumn{5}{|l|}{$139-856 \mathrm{~A}-$} \\
\hline $1 \mathrm{H}-1,74-77$ & 0.74 & 3.0 & 35.1 & 62.0 \\
\hline $1 \mathrm{H}-2,39-43$ & 1.89 & 1.1 & 27.0 & 72.0 \\
\hline $2 \mathrm{H}-1,67-69$ & 3.37 & 1.6 & 71.9 & 26.5 \\
\hline $2 \mathrm{H}-2,65-68$ & 4.85 & 0.7 & 37.7 & 61.6 \\
\hline $2 \mathrm{H}-3,86-89$ & 6.56 & 0.1 & 20.6 & 79.3 \\
\hline $2 \mathrm{H}-4,73-76$ & 7.93 & 0.1 & 46.1 & 53.8 \\
\hline $2 \mathrm{H}-5,64-66$ & 9.34 & 12.4 & 70.9 & 16.7 \\
\hline $2 \mathrm{H}-5,74-76$ & 9.44 & 9.0 & 17.6 & 73.4 \\
\hline $2 \mathrm{H}-6,74-76$ & 10.94 & 0.4 & 55.0 & 44.7 \\
\hline $2 \mathrm{H}-7,43-46$ & 12.13 & 0.7 & 62.8 & 36.5 \\
\hline $3 \mathrm{H}-1,24-27$ & 12.44 & 47.2 & 38.6 & 14.2 \\
\hline $3 \mathrm{H}-1,91-93$ & 13.11 & 0.7 & 41.7 & 57.7 \\
\hline $3 \mathrm{H}-2,60-62$ & 14.30 & 1.7 & 79.0 & 19.3 \\
\hline $3 \mathrm{H}-2,70-72$ & 14.40 & 0.3 & 38.9 & 60.8 \\
\hline $3 \mathrm{H}-3,57-59$ & 15.77 & 10.0 & 68.5 & 21.5 \\
\hline $3 \mathrm{H}-3,67-69$ & 15.87 & 0.4 & 14.1 & 85.5 \\
\hline $3 \mathrm{H}-4,46-48$ & 17.16 & 1.2 & 71.1 & 27.7 \\
\hline $3 \mathrm{H}-5,56-58$ & 18.76 & 0.4 & 22.7 & 76.9 \\
\hline $3 \mathrm{H}-5,69-70$ & 18.89 & 0.3 & 41.5 & 58.2 \\
\hline $3 \mathrm{H}-6,76-78$ & 20.46 & 5.3 & 18.9 & 75.8 \\
\hline $3 \mathrm{H}-7,41-43$ & 21.61 & 8.2 & 47.4 & 44.4 \\
\hline $4 \mathrm{H}-1,66-70$ & 22.36 & 1.2 & 38.4 & 60.4 \\
\hline $4 \mathrm{H}-2,56-60$ & 23.76 & 19.1 & 80.9 & - \\
\hline $4 \mathrm{H}-2,68-72$ & 23.88 & 0.0 & 75.9 & 24.1 \\
\hline $4 \mathrm{H}-3,71-75$ & 25.41 & 20.7 & 62.7 & 16.7 \\
\hline $4 \mathrm{H}-3,82-86$ & 25.52 & 0.3 & 58.9 & 40.9 \\
\hline $4 \mathrm{H}-4,74-78$ & 26.94 & 13.7 & 12.6 & 73.8 \\
\hline $4 \mathrm{H}-4,111-115$ & 27.31 & 53.3 & 31.5 & 15.2 \\
\hline $4 \mathrm{H}-5,73-77$ & 28.43 & 1.4 & 28.5 & 70.1 \\
\hline $4 \mathrm{H}-6,64-68$ & 29.84 & 48.1 & 37.9 & 14.1 \\
\hline $4 \mathrm{H}-6,94-98$ & 30.14 & 2.9 & 26.9 & 70.1 \\
\hline $4 \mathrm{H}-7,37-41$ & 31.07 & 18.8 & 26.4 & 54.9 \\
\hline $5 \mathrm{H}-2,58-62$ & 32.16 & 8.2 & 65.2 & 26.6 \\
\hline $5 \mathrm{H}-2,102-106$ & 32.60 & 4.6 & 26.2 & 69.2 \\
\hline $5 \mathrm{H}-3,67-71$ & 33.75 & 2.2 & 42.9 & 54.9 \\
\hline $5 \mathrm{H}-4,70-74$ & 35.28 & 5.7 & 51.2 & 43.1 \\
\hline $5 \mathrm{H}-5,48-52$ & 36.56 & 13.1 & 25.0 & 61.9 \\
\hline $5 \mathrm{H}-5,80-84$ & 36.88 & 16.1 & 64,1 & 19.7 \\
\hline $5 \mathrm{H}-6,50-54$ & 38.08 & 56.1 & 23.2 & 20.8 \\
\hline $5 \mathrm{H}-6,63-66$ & 38.21 & 0.7 & 55.3 & 44.1 \\
\hline $5 \mathrm{H}-7,67-70$ & 39.75 & 1.9 & 53.7 & 44.4 \\
\hline $5 \mathrm{H}-8,51-55$ & 41.09 & 2.5 & 55.2 & 42.3 \\
\hline $6 \mathrm{H}-1,60-64$ & 41.30 & 1.6 & 68.5 & 29.9 \\
\hline $6 \mathrm{H}-2,84-88$ & 43.04 & 6.3 & 65.7 & 28.0 \\
\hline $6 \mathrm{H}-2,97-101$ & 43.17 & 1.9 & 49.7 & 48.4 \\
\hline $6 \mathrm{H}-3,76-80$ & 44.46 & 56.1 & 11.1 & 32.8 \\
\hline $6 \mathrm{H}-3,107-111$ & 44.77 & 39.7 & 46.0 & 14.3 \\
\hline $6 \mathrm{H}-4,3 \mathrm{I}-35$ & 45.51 & 43.1 & 39.2 & 17.8 \\
\hline $6 \mathrm{H}-4,45-49$ & 45.65 & 1.3 & 69.9 & 28.8 \\
\hline $6 \mathrm{H}-5,65-69$ & 47.35 & 5.8 & 41.4 & 52.8 \\
\hline $6 \mathrm{H}-6,64-68$ & 48.84 & 0.3 & 70.7 & 29.0 \\
\hline $6 \mathrm{H}-6,77-81$ & 48.97 & 0.2 & 42.7 & 57.1 \\
\hline $6 \mathrm{H}-7,38-42$ & 50.08 & 22.7 & 32.1 & 45.3 \\
\hline $7 \mathrm{H}-1,39-43$ & 50.59 & 2.3 & 95.1 & 2.7 \\
\hline $7 \mathrm{H}-1,73-77$ & 50.93 & 7.4 & 26.5 & 66.1 \\
\hline $7 \mathrm{H}-2,82-86$ & 52.52 & 0.1 & 30.8 & 69.1 \\
\hline $7 \mathrm{H}-2,92-96$ & 52.62 & 25.6 & 56.0 & 18.4 \\
\hline $7 \mathrm{H}-3,73-77$ & 53.93 & 0.9 & - & 99.1 \\
\hline $7 \mathrm{H}-3,93-97$ & 54.13 & 1.0 & 29.7 & 69.3 \\
\hline $7 \mathrm{H}-4,39-43$ & 55.08 & 3.7 & 28.0 & 68.3 \\
\hline $7 \mathrm{H}-4,60-64$ & 55.30 & 43.4 & 34.1 & 22.5 \\
\hline $7 \mathrm{H}-5,82-86$ & 57.02 & 40.3 & 43.7 & 16.1 \\
\hline $7 \mathrm{H}-5,98-102$ & 57.18 & 4.6 & 14.8 & 80.6 \\
\hline $7 \mathrm{H}-6,72-76$ & 58.42 & 2.4 & 73.0 & 24.6 \\
\hline $7 \mathrm{H}-6,93-97$ & 58.63 & 0.4 & 48.7 & 51.0 \\
\hline $7 \mathrm{H}-7,26-30$ & 59.46 & 20.0 & 57.1 & 22.9 \\
\hline $7 \mathrm{H}-7,39-43$ & 59.59 & 0.2 & 28.6 & 71.2 \\
\hline $8 \mathrm{H}-1,90-93$ & 60.60 & 0.1 & 29.8 & 70.1 \\
\hline $8 \mathrm{H}-1,113-116$ & 60.83 & 16.7 & 83.3 & - \\
\hline $8 \mathrm{H}-2,65-68$ & 61.85 & 1.5 & 31.5 & 67.0 \\
\hline $8 \mathrm{H}-3,68-71$ & 63.38 & 0.0 & 29.9 & 70.1 \\
\hline $8 \mathrm{H}-3,99-102$ & 63.69 & 6.2 & 79.6 & 14.2 \\
\hline $8 \mathrm{H}-4,69-72$ & 64.89 & 2.3 & 41.4 & 56.3 \\
\hline $8 \mathrm{H}-5,70-73$ & 66.40 & 2.6 & 27.3 & 70.1 \\
\hline $8 \mathrm{H}-6,56-58$ & 67.76 & 26.0 & 62.4 & 11.5 \\
\hline
\end{tabular}


Table A1 (continued).

\begin{tabular}{|c|c|c|c|c|}
\hline \multirow{2}{*}{$\begin{array}{l}\text { Core, section, } \\
\text { interval }(\mathrm{cm})\end{array}$} & \multirow{2}{*}{$\begin{array}{l}\text { Depth" } \\
\text { (mbsf) }\end{array}$} & \multicolumn{3}{|c|}{$\begin{array}{c}\text { Normalized } \\
\text { dry weight }{ }^{\mathrm{b}}(\%)\end{array}$} \\
\hline & & Sand & Silt & Clay \\
\hline $8 \mathrm{H}-6,68-73$ & 67.88 & 6.4 & 58.5 & 35.1 \\
\hline $8 \mathrm{H}-7,37-39$ & 69.07 & 4.2 & 36.0 & 59.8 \\
\hline $9 \mathrm{H}-1,72-75$ & 69.92 & 4.2 & 39.6 & 56.2 \\
\hline $9 \mathrm{H}-2,40-44$ & 71.10 & 21.5 & 60.3 & 18.2 \\
\hline $9 \mathrm{H}-2,90-94$ & 71.60 & 2.3 & 35.3 & 62.5 \\
\hline $9 \mathrm{H}-3,59-61$ & 72.79 & 0.6 & - & 99.4 \\
\hline $9 \mathrm{H}-3,98-100$ & 73.18 & 3.0 & 76.9 & 20.2 \\
\hline $9 \mathrm{H}-4,71-75$ & 74.41 & 2.1 & 52.0 & 46.0 \\
\hline $9 \mathrm{H}-5,96-100$ & 76.16 & 2.2 & 62.5 & 35.3 \\
\hline $9 \mathrm{H}-6,39-41$ & 77.09 & 0.2 & 14.3 & 85.6 \\
\hline $9 \mathrm{H}-6,55-59$ & 77.25 & 2.9 & 81.5 & 15.6 \\
\hline $9 \mathrm{H}-7,23-27$ & 78.43 & 10.9 & 89.1 & - \\
\hline $10 X-1,71-74$ & 79.41 & 27.5 & 42.9 & 29.6 \\
\hline $11 X-1,87-89$ & 87.07 & 4.3 & 59.0 & 36.7 \\
\hline $11 X-2,31-33$ & 88.01 & 63.7. & 4.6 & 31.8 \\
\hline $11 \mathrm{X}-\mathrm{CC}, 14-16$ & 88.51 & 38.6 & 40.6 & 20.8 \\
\hline $13 \times-4,105-109$ & 110.85 & 1.3 & 49.0 & 49.7 \\
\hline \multicolumn{5}{|l|}{$139-856 \mathrm{~B}-$} \\
\hline 1H-1, 119-123 & 1.19 & 0.5 & 26.0 & 73.5 \\
\hline $2 \mathrm{H}-3,51-53$ & 5.31 & 4.3 & 41.6 & 54.2 \\
\hline $2 \mathrm{H}-5,82-84$ & 8.62 & 0.6 & 40.3 & 59.1 \\
\hline $2 \mathrm{H}-6,127-131$ & 10.57 & 0.3 & 34.3 & 65.3 \\
\hline $3 \mathrm{H}-2,26-30$ & 13.06 & 0.3 & 44.8 & 54.9 \\
\hline $3 \mathrm{H}-4,92-96$ & 16.72 & 0.5 & 6.4 & 93.2 \\
\hline $4 \mathrm{H}-5,106-109$ & 27.86 & 5.1 & 20.7 & 74.3 \\
\hline $4 \mathrm{H}-6,122-124$ & 29.52 & 0.5 & 42.1 & 57.4 \\
\hline $5 \mathrm{H}-3,24-27$ & 33.54 & 11.3 & 27.5 & 61.2 \\
\hline $5 \mathrm{H}-3,75-79$ & & 0.1 & 39.4 & 60.5 \\
\hline $5 \mathrm{H}-6,77-81$ & 38.57 & 3.1 & 9.1 & 87.8 \\
\hline $6 \mathrm{H}-2,5-9$ & 41.35 & 0.4 & 20.0 & 79.7 \\
\hline $6 \mathrm{H}-4,16-19$ & 44.46 & 0.2 & 18.4 & 81.4 \\
\hline $6 \mathrm{H}-6,126-128$ & 48.56 & 1.4 & 21.0 & 77.6 \\
\hline $7 \mathrm{H}-3,125-128$ & 53.55 & 0.6 & 30.5 & 68.9 \\
\hline $8 \mathrm{H}-3,103-105$ & 62.83 & 0.4 & 9.8 & 89.8 \\
\hline \multicolumn{5}{|l|}{$139.857 \mathrm{~A}-$} \\
\hline $1 \mathrm{H}-4,119-123$ & 7.59 & 18.1 & 21.5 & 60.5 \\
\hline $1 \mathrm{H}-5,56-60$ & 8.46 & 0.6 & 50.5 & 49.0 \\
\hline $2 \mathrm{H}-1,74-77$ & 12.14 & 3.0 & 30.6 & 66.4 \\
\hline $2 \mathrm{H}-5,76-79$ & 18.16 & 9.7 & 13.2 & 77.1 \\
\hline $4 \mathrm{H}-3,80-84$ & 25.70 & 4.2 & 81.7 & 14.1 \\
\hline $4 \mathrm{H}-4,39-43$ & 26.79 & 3.3 & 44.1 & 52.6 \\
\hline $4 \mathrm{H}-6,94-98$ & 30.34 & 19.0 & 81.0 & - \\
\hline $6 \mathrm{H}-1,72-76$ & 41.62 & 0.4 & 67.4 & 32.2 \\
\hline $6 \mathrm{H}-4,58-62$ & 45.98 & 0.2 & 47.7 & 52.1 \\
\hline $7 \mathrm{H}-3,63-67$ & 52.85 & 0.5 & 20.4 & 79.1 \\
\hline $7 \mathrm{H}-6,44-48$ & 56.12 & 10.0 & 54.7 & 35.4 \\
\hline $8 \mathrm{H}-2,87-90$ & 62.27 & 19.4 & 13.2 & 67.4 \\
\hline $8 \mathrm{H}-4,83-86$ & 65.23 & 17.3 & 2.0 & 80.7 \\
\hline $8 \mathrm{H}-6,88-91$ & 68.28 & 0.9 & 10.7 & 88.5 \\
\hline $8 \mathrm{H}-6,118-121$ & 68.58 & 17.7 & 77.5 & 4.8 \\
\hline $9 \mathrm{H}-4,65-68$ & 74.55 & 1.4 & 5.4 & 93.2 \\
\hline $9 \mathrm{H}-6,73-78$ & 77.63 & 0.4 & 70.0 & 29.6 \\
\hline $10 \mathrm{H}-2,66-68$ & 81.06 & 7.9 & 67.3 & 24.8 \\
\hline $10 \mathrm{H}-6,36-38$ & 86.76 & 26.1 & 52.1 & 21.8 \\
\hline $12 \mathrm{X}-\mathrm{CC}, 27-30$ & 92.17 & 5.1 & 40.6 & 54.4 \\
\hline $13 X-3,11-17$ & 105.63 & 0.5 & 75.6 & 23.9 \\
\hline \multicolumn{5}{|l|}{ 139-857C- } \\
\hline $2 \mathrm{R}-1,67-70$ & 57.17 & 5.9 & 23.7 & 70.4 \\
\hline $3 \mathrm{R}-1,86-88$ & 67.36 & 5.0 & 26.1 & 68.9 \\
\hline $3 R-3,34-36$ & 69.84 & 1.0 & 62.1 & 36.9 \\
\hline $9 \mathrm{R}-1,39-42$ & 114.89 & 19.8 & 47.6 & 32.7 \\
\hline $10 \mathrm{R}-1,39-41$ & 124.49 & 0.3 & 31.2 & 68.5 \\
\hline $12 \mathrm{R}-1,74-78$ & 144.24 & 0.0 & 30.2 & 69.7 \\
\hline $13 R-2,44-48$ & 155.04 & 0.6 & 90.7 & 8.7 \\
\hline $14 \mathrm{R}-2,23-27$ & 164.53 & 1.7 & 9.7 & 88.6 \\
\hline $15 \mathrm{R}-4,84-86$ & 177.84 & 1.4 & 39.7 & 59.0 \\
\hline $21 R-2,38-40$ & 232.48 & 12.9 & 87.2 & - \\
\hline
\end{tabular}

\begin{tabular}{|c|c|c|c|c|}
\hline \multirow{2}{*}{$\begin{array}{l}\text { Core, section, } \\
\text { interval }(\mathrm{cm})\end{array}$} & \multirow{2}{*}{$\begin{array}{l}\text { Deptha } \\
\text { (mbsf) }\end{array}$} & \multicolumn{3}{|c|}{$\begin{array}{c}\text { Normalized } \\
\text { dry weight }{ }^{\mathrm{b}}(\%)\end{array}$} \\
\hline & & Sand & Silt & Clay \\
\hline \multicolumn{5}{|l|}{$139-858 \mathrm{~A}-$} \\
\hline $1 \mathrm{H}-1,76-78$ & 0.76 & 2.6 & 41.0 & 56.5 \\
\hline $1 \mathrm{H}-2,32-34$ & 1.82 & 5.7 & 27.6 & 66.8 \\
\hline $2 \mathrm{H}-3,49-53$ & 5.89 & 4.9 & 25.5 & 69.6 \\
\hline $2 \mathrm{H}-5,93-96$ & 9.33 & 0.9 & 60.7 & 38.4 \\
\hline $3 \mathrm{H}-3,85-87$ & 15.52 & 0.4 & 56.0 & 43,6 \\
\hline $3 \mathrm{H}-6,87-90$ & 20.04 & 1.2 & 60.9 & 38.0 \\
\hline $4 \mathrm{H}-2,76-79$ & 23.66 & 7.7 & 42.3 & 50.1 \\
\hline $4 \mathrm{H}-4,47-50$ & 26.37 & 1.3 & 30.3 & 68.5 \\
\hline $4 \mathrm{H}-6,87-90$ & 29.77 & 3.6 & 34.9 & 61.5 \\
\hline $5 \mathrm{H}-3,97-100$ & 34.87 & 1.2 & 34.1 & 64.7 \\
\hline $5 \mathrm{H}-6,76-80$ & 39.16 & 5.6 & 34.5 & 60.0 \\
\hline $6 \mathrm{H}-1,114-116$ & 41.54 & 1.2 & 26.1 & 72.7 \\
\hline $6 \mathrm{H}-3,88-91$ & 44.28 & 2.7 & 47.8 & 49.5 \\
\hline $7 \mathrm{H}-4,84-88$ & 55.24 & 53.5 & 39.7 & 6.7 \\
\hline $7 \mathrm{H}-5,54-57$ & 56.44 & 1.1 & 41.9 & 57.0 \\
\hline $8 \mathrm{H}-2,31-33$ & 60.64 & 17.6 & 34.0 & 48.5 \\
\hline $9 \mathrm{X}-6,129-133$ & 71.29 & 28.2 & 54.5 & 17.3 \\
\hline $11 \mathrm{X}-\mathrm{CC}, 17-21$ & 73.64 & 0.9 & 57.9 & 41.2 \\
\hline \multicolumn{5}{|l|}{ 139-858B- } \\
\hline $1 \mathrm{H}-2,98-101$ & 2.48 & 4.4 & - & 95.6 \\
\hline $1 \mathrm{H}-3,73-76$ & 3.73 & 0.1 & 41.9 & 58.1 \\
\hline $1 \mathrm{H}-4,78-81$ & 5.28 & 0.1 & 14.7 & 85.2 \\
\hline $1 \mathrm{H}-5,60-63$ & 6.60 & 0.6 & 31.3 & 68.1 \\
\hline $2 \mathrm{H}-2,121-124$ & 9.91 & 1.5 & 22.6 & 76.0 \\
\hline $2 \mathrm{H}-4,62-64$ & 12.32 & 2.9 & 36.6 & 60.6 \\
\hline $2 \mathrm{H}-5,16-18$ & 13.36 & 12.0 & 74.8 & 13.2 \\
\hline $2 \mathrm{H}-6,75-77$ & 15.45 & 2.9 & 23.6 & 73.4 \\
\hline $2 \mathrm{H}-7,73-76$ & & 0.4 & 52.8 & 46.8 \\
\hline $5 \mathrm{H}-1,117-121$ & 25.07 & 3.0 & 29.0 & 68.0 \\
\hline $5 \mathrm{H}-3,118-121$ & 28.08 & 13.5 & 29.2 & 57.3 \\
\hline $5 \mathrm{H}-4,27-31$ & 28.67 & 6.3 & 39.7 & 54.0 \\
\hline \multicolumn{5}{|l|}{$139-858 \mathrm{C}$} \\
\hline $1 \mathrm{H}-2,38-42$ & 1.88 & 6.5 & 29.4 & 64.1 \\
\hline $1 \mathrm{H}-3,17-21$ & 3.17 & 1.6 & 41.7 & 56.8 \\
\hline $2 \mathrm{H}-1,88-91$ & 4.38 & 9.1 & 29.6 & 61.3 \\
\hline $2 \mathrm{H}-6,78-8 \mathrm{I}$ & 11.78 & 5.0 & 71.6 & 23.5 \\
\hline $3 \mathrm{H}-1,13-16$ & 13.13 & 3.3 & 58.0 & 38.7 \\
\hline $3 \mathrm{H}-2,136-139$ & 15.86 & 8.8 & 35.8 & 55.4 \\
\hline $3 \mathrm{H}-3,107-109$ & 17.07 & 6.3 & 54.1 & 39.6 \\
\hline $3 \mathrm{H}-4,77-80$ & 18.27 & 18.6 & 44.7 & 36.7 \\
\hline $3 \mathrm{H}-6,86-89$ & 21.36 & 28.8 & 48.8 & 22.3 \\
\hline $5 \mathrm{H}-1,72-75$ & 24.22 & 20.4 & 48.4 & 31.3 \\
\hline $5 \mathrm{H}-2,106-108$ & 26.06 & 2.6 & 55.1 & 42.3 \\
\hline $5 \mathrm{H}-3,19-21$ & 26.69 & 5.8 & 45.0 & 49.2 \\
\hline $5 \mathrm{H}-4,93-95$ & 28.93 & 9.4 & 37.5 & 53.1 \\
\hline SH-5, $88-90$ & 30.38 & 11.1 & 50.4 & 38.6 \\
\hline $6 \mathrm{H}-1,80-82$ & 33.80 & 43.7 & 56.3 & - \\
\hline $6 \mathrm{H}-3,108-110$ & 37.08 & 0.1 & 42.3 & 57.7 \\
\hline $7 \mathrm{H}-1,11-12$ & 41.61 & 27.1 & 20.3 & 52.6 \\
\hline \multicolumn{5}{|l|}{$139-858 \mathrm{D}$} \\
\hline $1 \mathrm{H}-1,103-107$ & 1.03 & 13.1 & - & 87.0 \\
\hline $1 \mathrm{H}-3,112-115$ & 4.12 & 2.3 & 30.6 & 67.1 \\
\hline $1 \mathrm{H}-4,80-83$ & 5.30 & 5.5 & 34.0 & 60.5 \\
\hline 1H-5, 106-110 & 7.06 & 0.3 & 45.9 & 53.8 \\
\hline IH- $6,25-28$ & 7.75 & 26.3 & 20.1 & 53.6 \\
\hline $2 \mathrm{H}-1,128-131$ & 10.58 & 1.0 & 11.9 & 87.1 \\
\hline $2 \mathrm{H}-2,95-98$ & 11.75 & 8.3 & 52.7 & 39.0 \\
\hline $2 \mathrm{H}-3,133-136$ & 13.63 & 4.4 & 32.5 & 63.1 \\
\hline $2 \mathrm{H}-4,57-60$ & 14.37 & 2.2 & 9.9 & 88.0 \\
\hline $2 \mathrm{H}-5,36-39$ & 15.66 & 0.7 & 19.2 & 80.2 \\
\hline $2 \mathrm{H}-6,93-96$ & 17.73 & 22.9 & 35.4 & 41.7 \\
\hline $2 \mathrm{H}-7,14-16$ & 18.44 & 7.2 & 32.6 & 60.2 \\
\hline $4 \mathrm{H}-3,107-110$ & 22.61 & 12.2 & 24.0 & 63.9 \\
\hline $4 \mathrm{H}-5,35-38$ & 24.89 & 20.6 & 25.1 & 54.4 \\
\hline $4 \mathrm{H}-6,26-29$ & 26.30 & 37.9 & 30.8 & 31.3 \\
\hline
\end{tabular}

a Depths are listed for the top of the sampled interval.

Rounding errors cause normalized weights to total $100.0 \% \pm 0.1 \%$. 